\title{
State of Art on Bioimaging by Nanoparticles in Hyperthermia and Thermometry: Visualization of Tissue Protein Targeting
}

\author{
R. Sharma*,1,2, A. Sharma ${ }^{3}$ and C.J. Chen ${ }^{1}$ \\ ${ }^{1}$ Center of Nanomagnetics and Biotechnology, Florida State University, Tallahassee, FL 32310, USA \\ ${ }^{2}$ Innovations And Solutions Inc. USA and Tallahassee Community College, Tallahassee, FL 32304, USA \\ ${ }^{3}$ Nanotechnology Lab, Electrical Engineering Department, CATE, Maharana Pratap A\&T University, Udaipur, \\ Rajasthan, India
}

\begin{abstract}
Heating tumors by nanoparticles and resistance in tumor cells to a high temperature is emerging as an effective tool as nanomedicine tool in cancer therapy. The art of thermal mapping in a tumor at various locations is emerging as the selective approach of hyperthermia to monitor temperature and treat the tumor. However, thermometry and tumor cell interaction with nanoparticles may monitor and evaluate the tumor cell survival after exposure to high physiological temperatures but show cytotoxicity. The design and application of 10-100 nano meter sized nanoparticles in tumor hyperthermia has emerged as an effective technology in hyperthermia imaging and treatment. The temperature and nanoparticle magnetic moment relationship is specific. Furthermore, there are two main issues that are unsolved as of yet. First issue is the relationship of tumor energy changes due to tumor magnetization by different nanoparticles. The second issue is the heat transfer behavior of the nanoparticle inside the tumor combined with hyperthermia and efficacy of combined modality on the tumor tissue temperature rise. In present study, we highlight that in vivo imaging such as MR thermometry, photoacuastic mapping of different tumor locations solve these issues to some extent. The art of combined use of hyperthermia by nanoparticles with hypoxia sensitive nitroimidazole radiosensitizers with chemotherapeutic drugs is highlighted to have a great impact on public health as alternative therapeutic oncology and monitoring therapy.
\end{abstract}

Keywords: Tumor, oncology, hypoxia, hyperthermia, nanoparticles, thermal therapy.

\section{INTRODUCTION}

Heating of organs and the destruction of cancer by thermal therapy and chemotherapy is an present art of radiation therapy [1]. Several technical reviews reference the tissue heating by nanoparticle based hyperthermia to tumors [2-10]. These studies paved the way to a rapid development in therapeutic applicator design and sophistication of hyperthermia equipment [11-13]. The tumor cells behave both as radiation resistant as well as hypoxic and oxygen deficient. It makes tumor cells sensitive to radio-sensitization and nanoparticle therapy as tumor cells show toxicity to nanoparticles $[14,15]$. In this direction, recently, the role of gadolinium, iron oxide, zinc inorganic elements has emerged where these nanoparticles can target proteins of tissues including heart, kidneys, skin, brain [16-28]. A new terminology was proposed as "paramagnetic nanoparticle targeted hyperthermia and thermometry". These nanoparticles enhance the diagnosis and localization of specific tissue characteristics by multimodal imaging techniques including optical, magnetic resonance, positron emission tomography, computed tomography and X-ray techniques [29-38]. However, tumor heating by placing multifunctional nanoparticles at tumor sites (hyperthermia) is emerging as an art of tumor treatment by "multimodal nanothermal therapy" [39-41]. In general, two

\footnotetext{
*Address correspondence to this author at the Amity Institute of Nanotechnology, Amity University UP, NOIDA; Tel: 1-850-590-1052; Fax: 1-850410-6964; E-mails: rksz2004@gmail.com,rksz2004@yahoo.com
}

main considerations have emerged: 1 . longer stay time of the nanoparticles closer to tissue cell proteins such as basement membrane proteins, is the main key of an effective agent as a hyperthermia agent; 2 . to use the nanoparticles to monitor temperature sensitive physical and proteomic metabolomic changes in tissue at different locations. In this direction, colloidal gold-thiol preparations were first reported as effective staining agents to label proteins in both diagnostics such as imaging, blotting, flow cytometry, hybridization assays and gold-thiol hyperthermia agents [42-45]. Other potential hyperthermic particles are silver, iron, zinc and lanthanum nanoparticles [46]. Presently, colloidal gold particles are used in monitoring metabolic changes as bound with antibodies, lipids during cellular uptake and endocytosis [47, 48]. Carbon nanotubes were reported in thermal ablation of malignant tissue with DNA encaged carbon nanotubes [49].

\section{Techniques of Tumor Targeting and Therapy}

Recently, the focus is diverted to molecular targeting by introducing peptide or polynucleotide bound nanoparticles [44]. Another approach is direct injection of antibody bound nanoparticles at the tumor site with a high degree of specificity with minimum effect on healthy tissues $[50,51]$. The in vivo therapeutic utility of nanoparticles is growing based on energy utilization from different sources of magnetic fields, microwaves, lasers and ultrasound to the tumor tissue [5254]. These external energy sources have an additional advantage to display hyperthermia effects if applied at various strengths to the nanoparticle concentrations [55]. 
To understand the energy deposition to tumor and hyperthermia effect can be explained as a multifactorial physical process.

\section{Energy Deposition to the Tumor by Hyperthermia}

Adjunctive therapy: The primary hyperthermia approach was limited due to two reasons: 1. Nanoparticle induced collateral damage, and 2. Limited tumor penetrance. These limitations are further complicated due to tumor type and location. Therapeutic hyperthermia is in practice by using laserinduced hyperthermia [56], microwave induced [57, 58], hysteretic magnetic heating [59,60] and localized nanoparticle delivery [61, 62]. However, hyperthermia has limitations. Most of available hyperthermia therapy, both systemic and targeted, has been reported as adjunctive therapy to support radiotherapy or chemotherapy [63]. Several reasons of tissue damage are reported as to the limited success of hyperthermia [64-66]; a few have been mentioned in this review and shown in Table 1.

Use of an external microwave antenna induced energy deposition by diffusion in a broader effective field including healthy tissue and resulted in poor localized focused energy deposition [12]. The use of antenna and emitters in hyperthermia equipment may produce limited but undesirable necrosis. However, the energy transfer by magnetic materials either injected or implanted into the tissue results with deposition was insufficient to cause tumor necrosis. Recently a multifunctional approach has been suggested for the use of thermal energy deposition from magnetic nanoparticles along with dendritic cell therapy in melanoma with $60 \%$ regression of tumors [67]. Now, ample evidence exists to demonstrate the progressive apoptosis in cells exposed to elevated temperature in the range of $5-10{ }^{\circ} \mathrm{C}$ [68]. In this direction, major success of magnetic mediated hyperthermia $(\mathrm{MMH})$ has addressed the diffusion coefficient, cell volume, and the buoyancy ratio to play significant roles on the characterization of the mass and heat transfer mechanisms within the cell targeting and desired heat distribution across the tumor areas [69].

\section{Magnetic Hyperthermia}

In principle, coupling of the external RF magnetic field to the magnetic particles result in energy transferred to the tissue by a local magnetic fields interaction with the tissue to induce tissue protons from lower energy to higher energy states. However, the efficiency depends on balance between the rate of thermal energy deposition and the thermal dissipation in tissue. The nanoparticle induced shift to a higher energy in tissue causes change in moments and paramagnetic behavior imparting the magnetic hyperthermia effect due to Neel relaxation and hysteretic heating in the tissue [70]. The nanoparticle paramagnetic property is valuable in both diagnostic magnetic resonance effect and particle induced tissue killing by membrane and nuclear damage [71]. In a recent report, an external RF field was shown to cause global heating in a particle infused tissue by a resistive heating mechanism of energy transfer by $100 \mathrm{~nm}$ iron oxide particles in a tumor located in rabbit liver [72].

Let us consider how magnetic nanoparticle-induced energy transfer may cause oxygen starved tumor cells to undergo necrosis while minimizing same time collateral damage to healthy tissue due to thermal diffusion. Mainly three mechanisms are known for variable magnetic field induced hyperthermia in nanoparticle impregnated tumor tissue: 1 . electromagnetic induced ohmic currents flowing in conducting media; 2 . hysteretic effect by traversed magnetic hysteresis loop of magnetic materials; 3 . viscosity induced resistance due to slow movement of nanoparticles in viscous medium [73]. However, other possibilities are dielectric heating, spin torsion effects, etc.

\section{Physical Basis of Hyperthermia}

From physics point of view, resistance, $(\mathrm{R})$ containing magnetic nanoparticles with average magnetization (M) subjected to a specifically uniform dipolar magnetic field with strength, $\left(\mathrm{B}_{0}\right)$ rotating with frequency $(\omega)$. The rate of deposition for hyperthermia ( $\mathrm{dQ}_{\text {hyperthermia }} / \mathrm{dt}$ ) may be written as:

$\frac{\mathrm{dQ}}{\mathrm{dt}}$ hyperthermia $\sim \mathrm{R}\left(\mathrm{wB}_{0}\right)_{2}$,

Eq. 1

where $\mathrm{dQ}_{\mathrm{hypermia}}$ may be due to ohmic or hysteresis or viscosity effects.

In magnetic fields, the heating effect due to hysteresis may be generated by switching an external magnetic field back and forth or external magnetic field angular rotation of field. In contrast, the magnetic field may be varied by angular rotation to get maximum energy transfer by viscous mechanism at critical rotation frequency:

$\omega_{\text {critical }}=\mathrm{MB}_{0} / 6 \eta$,

Eq. 2

Table 1. Emerging Thermal Mapping Applications in Hyperthermia Monitoring

\begin{tabular}{|l|l|l|}
\hline Modality of thermal mapping and hyperthermia & Physical property & Energy deposited \\
\hline \hline Alternating Current & Dielectric & Heating \\
\hline Laser/Microwave & Diffusion & Thermal \\
\hline Ultrasound & Echo & Ultrasound \\
\hline X-ray/CT & Attenuation & Photon \\
\hline MRI & Phase/moment & Hysteresis \\
\hline Optical/Molecular imaging & Fluorescence/Luminescence/Chemiluminescence & Molecular-interaction \\
\hline Nanoparticle & Magnetic & Thermal \\
\hline
\end{tabular}


where $\eta$ is the viscosity of the fluid in which nanoparticles are prepared. The maximum viscous energy transfer rate is given by:

$\underline{\mathrm{dQ}}_{\text {viscous (max) }} \sim 4 / 3 \pi \mathrm{a}^{3} \mathrm{~B}_{0} \mathrm{M} \omega_{\text {critical }}$,

Eq. 3

$\mathrm{dt}$

The critical frequency, $\left(\omega_{\text {critical }}\right)$ represents the maximum rotational frequency attainable for given nanoparticles magnetization, external field and fluid viscosity. This occurs when drag on rotating particle is equal to the coupling force between the external magnetic field and the nanoparticle. The two major tissue heating effects including hysteretic and viscous effects of hyperthermia are highlighted.

The main difference between hysteretic and viscous heating rates is the nanoparticle induced magnetization and nanoparticle moment magnitude. If moment is more than the external drive field will result in viscous heating. In general, $\mathrm{B}_{\mathrm{o}}$ is $\sim 10^{-2}$ to $10^{-1} \mathrm{~T}$ while nanoparticles it can reach up to 1 $\mathrm{T}$ and favors $\mathrm{M}$ and $\mathrm{B}_{\mathrm{o}}$ attained quick or viscous heating $>$ hysteretic heating for heat absorption in tissue. However, other minor factors are remnant magnetization $\left(\mathrm{B}_{\mathrm{r}}\right)$ due to no external field and coercivity factor $\left(\mathrm{H}_{\mathrm{c}}\right)$ due to locked magnetization vector. Superparamagnetic property is crucial due to its minimum $\mathrm{H}_{\mathrm{c}}$ to cause hysteretic heating as a result of flipping or rotation of particle alignment.

The nonparamagnetic viscous energy deposition is property due to maximum $\mathrm{H}_{\mathrm{c}}$ pinned to the lattice of the nanoparticle in a rotating external magnetic field and torque in the direction of rotation. The torque and friction between the nanoparticle and the viscous fluid will result with energy transfer from external magnetic field to the fluid mediated by the nanoparticle. Another issue of viscosity is also important related with nanoparticle interaction with tumor tissue. Several mechanisms of nanoparticle-tumor tissue interaction are reported such as cell receptor, bonding energy $\sim 6 \mathrm{keV}$ to make free the nanoparticle to rotate as given by,

$\mathrm{E}_{\mathrm{rot}}=8 / 3 \pi \mathrm{a}^{3} \mathrm{~B}_{0} \mathrm{M}$,

Eq. 4

Where $B_{0}$ is external field and $M$ is moment.

Ohmic heating and local viscous heating 'simulation model' was reported by simulated temperature rise in tissue induced by viscous energy upto $\mathrm{T}_{\text {global }}=3{ }^{\circ} \mathrm{C}$ causing tumor temperature $\mathrm{T}_{\text {tumor }} 25^{\circ} \mathrm{C}$. The tumor of $1 \mathrm{~cm}^{2}$ size was injected with $10^{6}$ spherical nanoparticles of $500 \mathrm{~nm}$ size with remnant magnetization of $0.9 \mathrm{~T}$ for molecular targeting. The tumor tissue with nanoparticles centered inside large volume as construct inside global rotating magnetic field. The applied rotation frequency and magnetic field applied displayed significant temperature distribution generated by viscous energy to cause necrosis [74]. In this magnetic hyperthermia process, focused and self controlled hyperthermia may also cause the spot overheating and local necrosis. However, the self control of overheating behavior depends on magnetic materials and their Curie temperature.

At our lab, we achieved AC magnetic field application with radiofrequency $100 \mathrm{kHz}-1 \mathrm{MHz}$ in hyperthermia [75]. The hyperthermia application methods such as radiofrequency (RF, 10-100 MHz), microwave ( $>300 \mathrm{MHz}$ ), ultrasound applicators, or infra-red (superficial and whole body hyperthermia) are useful for non-invasive heating. However, these methods suffer from boundary effects in regions of large perfusion such as brain tumors. Another factor is the specific absorption rate (SAR) that reduces the effective hyperthermia dose in the tumors of the liver, kidney, and the lung. Today, multimodal treatment schemes of radiation and/ or chemotherapy are available with great potentials of therapeutic advantages in several clinical studies.

The rotating nanoparticles deposit enough energy in the tumor to raise temperature to a level to cause necrosis. This effect may prevent thermal diffusion and minimize damage to healthy tissue. However, nanoparticle concentrations in healthy tissue also cause intracellular heating. Nanoparticle targeting is reported in vivo as nanoparticle specificity of 10:1 could cause global heating $10 \%$ of localized heating of tumor. The global heating can be minimized in rotated external magnetic field at the tumor site. The present trend is to develop and design variable global/localized magnetic field patterns and rotating field distribution over the nanoparticle impregnated tissue. The possibility of this rotating field distribution seems to enhance and localize energy deposition in the desired tumor area [76]. However, this approach has some presumptions: 1. Spherical shape of nanoparticles in uniform viscous medium; 2. Particle motion in Rf drive conditions; 3 . Generated heating rates; 4. Motion polarization, applied bias, magnetic fields, dipole coupling of particles, finite particle inertia, random external forces [77]. A radiofrequency coil set combined with a modest bias field is an ideally effective $r f$ drive technique better than circular rotation [78].

\section{Molecular Mechanisms of Magnetic Nanoparticle Heat- ing}

Magnetic nanoparticles (MNP) generate cellular changes mainly at membrane, nuclear, cytosketal structures to result apoptosis [68]. Cytokines, inflammatory molecules and protein synthesis play a role in heating mechanism based on four physical interactions: 1. generation of eddy currents in magnetic particles with size $>1 \mu, 2$. hysteresis losses in magnetic particles $>1 \mu$ and multidomain magnetic particles, 3 . Brownian and Neel relaxation losses in 'superparamagnetic' single-domain magnetic particles, 4. frictional losses in viscous suspensions. The relaxation in interacting nanoparticle systems was described [79].

The relaxation losses can be written as effective relaxation:

$$
\tau^{-1}=\tau_{N}^{-1}+\tau_{B}^{-1}
$$

Where $\tau \mathrm{N}$ is Neel relxation and $\tau \mathrm{B}$ is Brownian relaxation time. These can be written as:

$$
\begin{aligned}
\tau_{N} & =\frac{\sqrt{\pi}}{2} \tau_{0} \frac{\exp (T)}{\sqrt{\Gamma}} \\
\tau_{B} & =\frac{3 \eta V_{H}}{k T}
\end{aligned}
$$

Where $\tau_{0}$ is average relaxation time in response to a thermal fluctuation, $\eta$ is the viscosity of medium; $V H$ is the hydrodynamic volume of MNP; $k$ is the Boltzmann constant, $1.38 \times 10^{-23} \mathrm{~J} / \mathrm{K} ; T$ is the temperature. Here, $\Gamma=K V M / k T$ and $V M$ is the volume of MNP. 
Total dissipated energy of MNPs in alternating magnet can be written as:

$$
P=\pi \mu_{0} \chi_{0} H_{0}^{2} f \frac{2 \pi f \tau}{1+(2 \pi f \tau)^{2}}
$$

where $\mu_{0}$ is the permeability of free space, $4 \pi \cdot 10^{-7} \mathrm{~T} \mathrm{~m} / \mathrm{A} ; \chi_{0}$ is the equilibrium susceptibility; $H$ and $f$ are the amplitude and the frequency of alternating magnetic field.

The net temperature rise can be written as

$$
\Delta T=P \Delta t / \rho c_{P}
$$

Where $\rho$ and $C_{P}$ are the effective density and the effective specific heat calculated as $\rho=\varphi \rho_{1}+(1-\varphi) \rho_{2}$ and $\mathrm{C}_{\mathrm{P}}=\varphi \mathrm{CP}_{1}$ $+(1-\varphi) \mathrm{C}_{\mathrm{P} 2}$, where subscripts 1 and 2 represent the MNPs and the medium, respectively.

\section{Tissue Temperature Mapping and Measurement Tech- niques}

Initially proton MRI phase thermometry was reported in vivo [80]. The temperature distribution in the treated tissue is crucial to the therapy control, treatment outcome and minimizing damage to healthy tissue and organs [81]. The inserted temperature probe at the tissue site still remains as the method of choice; such as use of magnetic insensitive fiberoptic probe at a variable magnetic field [82]. Still these methods give information of only a single point measurement in the tissue without temperature distribution. Thermochromic fluorescent films and optical films are other available options [83]. Still challenge of thermal imaging remains at large for the range of milli kelvins within millisecond temporal resolution [84]. Recently several magnetic resonance image characteristics have come into light such as $\mathrm{pH}$, phase contrast, spin relaxivities, etc. for MRI thermometry up to $0.5^{\circ} \mathrm{C}$ of varying temperature resolution [85]. A new temperature-sensitive contrast mechanism was proposed for Curie temperature transition-based imaging using 6-fold iron (II) complexes as paramagnetic contrast agents above Curie temperature as shown in Fig. (1) [86]. Using molecular diffusion, temperature mapping was used to monitor hyperthermia effect by magnetic resonance imaging. Due to compatible RF fields, thermometry and hyperthermia both may be an ideal multimodal application of MRI during tumor monitoring and treatment [52].

\section{Application of Magnetic Nanoparticles for the Hyper- thermia Application}

The enhanced hyperthermia efficiency by nanomagnetic particles at Curie temperature $42-43^{\circ} \mathrm{C}$ was reported as selective heat source at the tumor site exposed to an alternating field [86]. Recently, Zn Ferrite nanoparticles have gained a lot of consideration mainly because of their ability to vary their properties at different proportions of the constituent metals in nanoparticle complex [87, 88]. Other issue was their non-biocompatibility. These particles are easily recognized by the phagocytic cells located in reticuloendothlial system (RES) as foreign products and are quickly removed from blood circulation $[68,89]$. To solve this problem, these magnetic nanoparticles were encapsulated in a polymeric bound protein shell to ensure longer sustenance of the particles within the body such as polyethylene glycol (PEG), polyvinyl alcohol, PLA-PEG (poly lactic acid - polyethylene

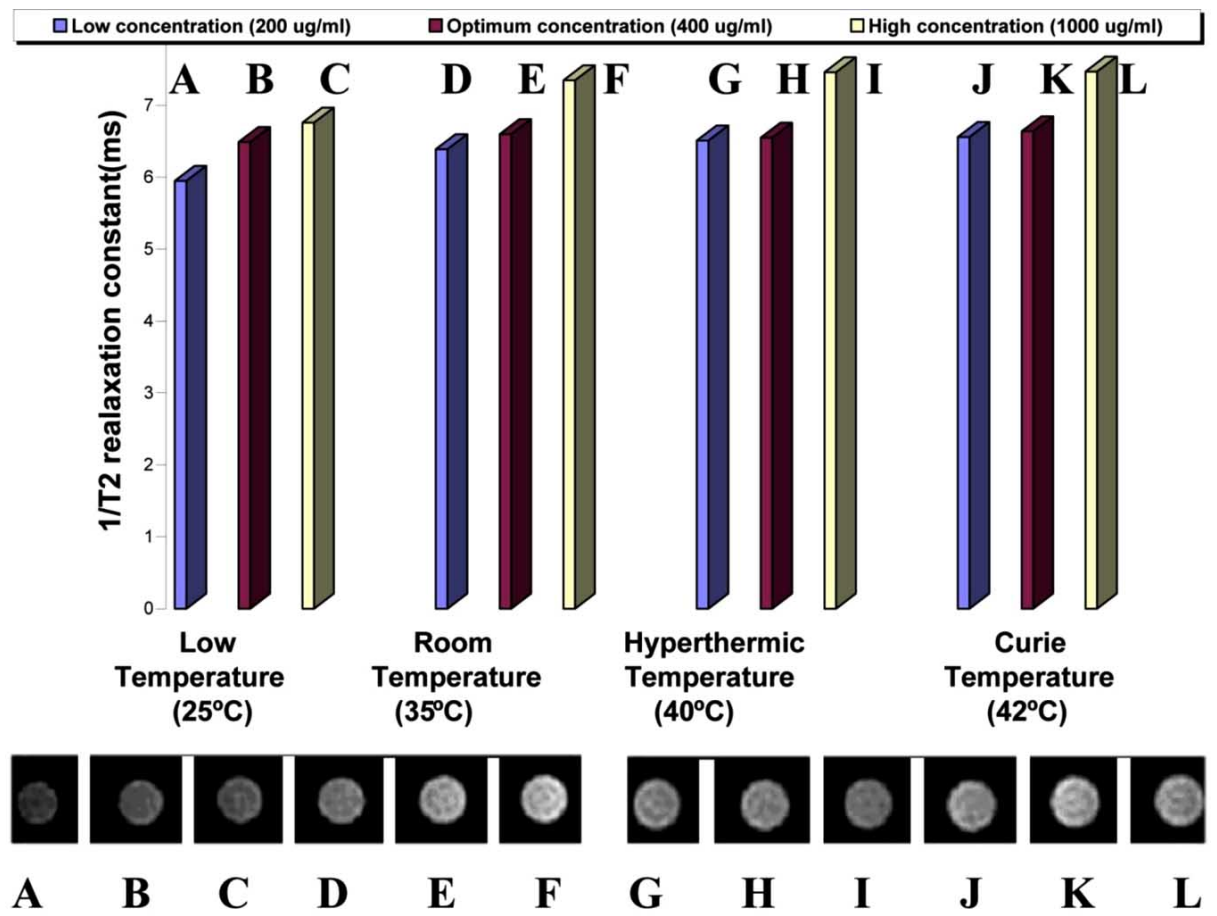

Fig. (1). On top: The relaxation constants $1 / \mathrm{T} 1$ at different temperatures are shown for different concentrations of nanoparticles in tubes as shown in Table 2. Notice the increased concentrations at Curie temperature show distinct MRI signal intensity. At bottom: The MRI images (a-c) at $25^{\circ} \mathrm{C} ;(\mathbf{d}-\mathbf{f})$ at $35^{\circ} \mathrm{C} ;(\mathbf{g}-\mathbf{i})$ at $40^{\circ} \mathrm{C} ;(\mathbf{j}-\mathbf{l})$ at $\left.42^{\circ} \mathrm{C}\right)$ of nanoparticle concentrations $200,400,1,000 \mathrm{microgm} / \mathrm{mL}$ are shown to establish the MRI signal intensities can visualize hyperthermia condition in tissue.Reproduced from Ref [9]. 


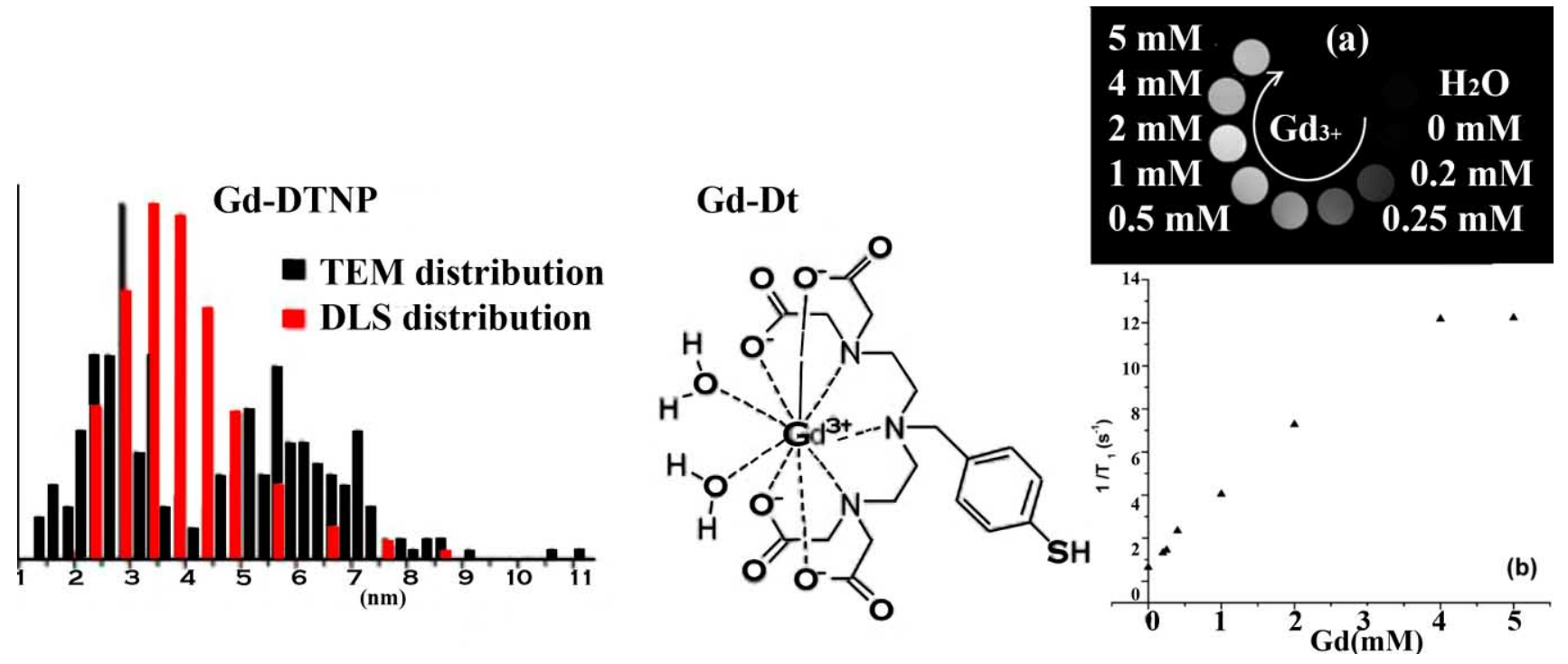

Fig. (2). (left) Diameter size distributions obtained from (black) TEM images and (red) DLS. (right) Chelating unit Dt complexed with gadolinium (Gd-Dt).

(a) T1-weighted magnetic resonance images of water as negative control (H2O) and of aqueous colloids of Au-DTDTPA-Gdx with increasing amount of $\mathrm{Gd}$ (from $0(\mathrm{x}) 0)$ to $5.00 \mathrm{mM}(\mathrm{x} \approx 50$ per particle), [Au] $) 50.7 \mathrm{mM})$. (b) Water proton longitudinal relaxation rate (1/T1) of Au-DTDTPA-Gdx as a function of increasing gadolinium concentration Reproduced with permission from reference [134].

glycol) and PLAPEG-PLA, PLGA (poly lactic glycolide) as a coating polymeric material [90].

\section{Temperature Dependence of Magnetization}

The temperature dependence of nanoparticle magnetization exhibited the superimposed plots for all the samples at Curie temperature calculated by extrapolation of the linear sections of the temperature dependence plots [91]. However, the higher Gd proportion showed bell shape with tempera- ture variation in range of Curie temperature as shown in Fig. (2). The magnetic moments of nanoparticles served as a function of T2 relaxation time as shown in Table 2.

In present paper, our emphasis is limited to $\mathrm{Mn}-\mathrm{Zn}-\mathrm{Gd}$ ferrite particles and their magnetic moments at different temperatures as shown in Fig. (2). The relationship of magnetic moments with temperature provides a tool of thermal mapping by MRI imaging. Moreover, MRI image intensity of these particles was dependent on their concentration as

Table 2. Specific $T_{2}$ Relaxivities of these Mn-Zn-Gd Ferrite Particle Samples at Different Concentrations at Different Temperatures in the Range of $25^{\circ}, 35^{\circ}, 40^{\circ}, 42^{\circ}$ and $45^{\circ} \mathrm{C}$ Specifically Near to the Curie Temperature. The Temperature $\Delta \mathrm{T}$ Changes the NMR Phase Shift $\Phi$ by Following Relationship for $500 \mathrm{MHz}: \Delta \phi=\alpha \cdot \gamma \cdot B_{0} \cdot(360 \%$ cycle) $\cdot$ TE $\cdot \mathrm{DT}$

\begin{tabular}{|c|c|c|c|}
\hline Concentration (in $\mu \mathrm{g} / \mathrm{ml})$ & Temperature $\left({ }^{\circ} \mathbf{C}\right)$ & FWHM (ppm) & T2 Relaxivity* (ms) \\
\hline \hline 200 & 25 & 0.2640 & 1680 \\
\hline 400 & & 0.2830 & 1540 \\
\hline 1000 & 35 & 0.3246 & 1565 \\
\hline 200 & & 0.2745 & 1515 \\
\hline 400 & 40 & 0.2984 & 1360 \\
\hline 1000 & & 0.3626 & 1535 \\
\hline 200 & & 0.2840 & 1525 \\
\hline 400 & & 0.2930 & 1340 \\
\hline 1000 & 42 & 0.3755 & 1524 \\
\hline 200 & & 0.2865 & 1505 \\
\hline 400 & & 0.3045 & 1339 \\
\hline 1000 & & 0.3760 & \\
\hline
\end{tabular}

*The $\mathrm{T}_{2}$ relaxivity was measured by the relationship between FWHM and $\mathrm{T} 2$ by expression $\mathrm{FWHM}=3.14 \mathrm{X} / T_{2}$ in units of rad sec ${ }^{-1}$ where $\mathrm{X}$ is dilution factor to prepare different concentrations of nanoparticles in tubes. 
shown in Fig. (3). The relationship of MRI signal intensity and nanoparticle concentration can be used as measurement of image contrast property as shown in Fig. (4).

$\mathrm{Mn}-\mathrm{Zn}$-ferrite particles and Gd substituted Mn-Zn- Ferrite particles were reported via chemical co-precipitation and ferritization [92]. These were characterized for hysteresis curves and temperature dependence of magnetization. On an average, their size was measured in the range of $20-200 \mathrm{~nm}$ by using TEM. The TEM clearly showed the inner parts of nanoparticle spheres containing metal contents. These particles were characterized for hysteresis curves and temperature dependence of magnetization.

The encapsulated magnetic nanoparticles showed effectiveness of nanoparticle thermal heating at elevated temperatures. However, nanoparticles as a polymer/protein complex showed selective breakage at elevated temperatures. As an example, the nanoparticle thermal heating is shown with distinct temperature responses at different duration of two types of particles (Mn-Gd-Ce) and (Fe-Co-Fe) at $1076 \mathrm{kHz}$ and $595 \mathrm{kHz}$, respectively.

The Gd substituted $\mathrm{Mn}-\mathrm{Zn}$ ferrites with various $\mathrm{Zn}$ and Gd proportions showed their effect on their magnetic properties and Curie temperature suitable for hyperthermia application. However, saturation magnetization of the particles was decreased with increased Gd proportion. The initial increase in the saturation magnetization can be speculated that the
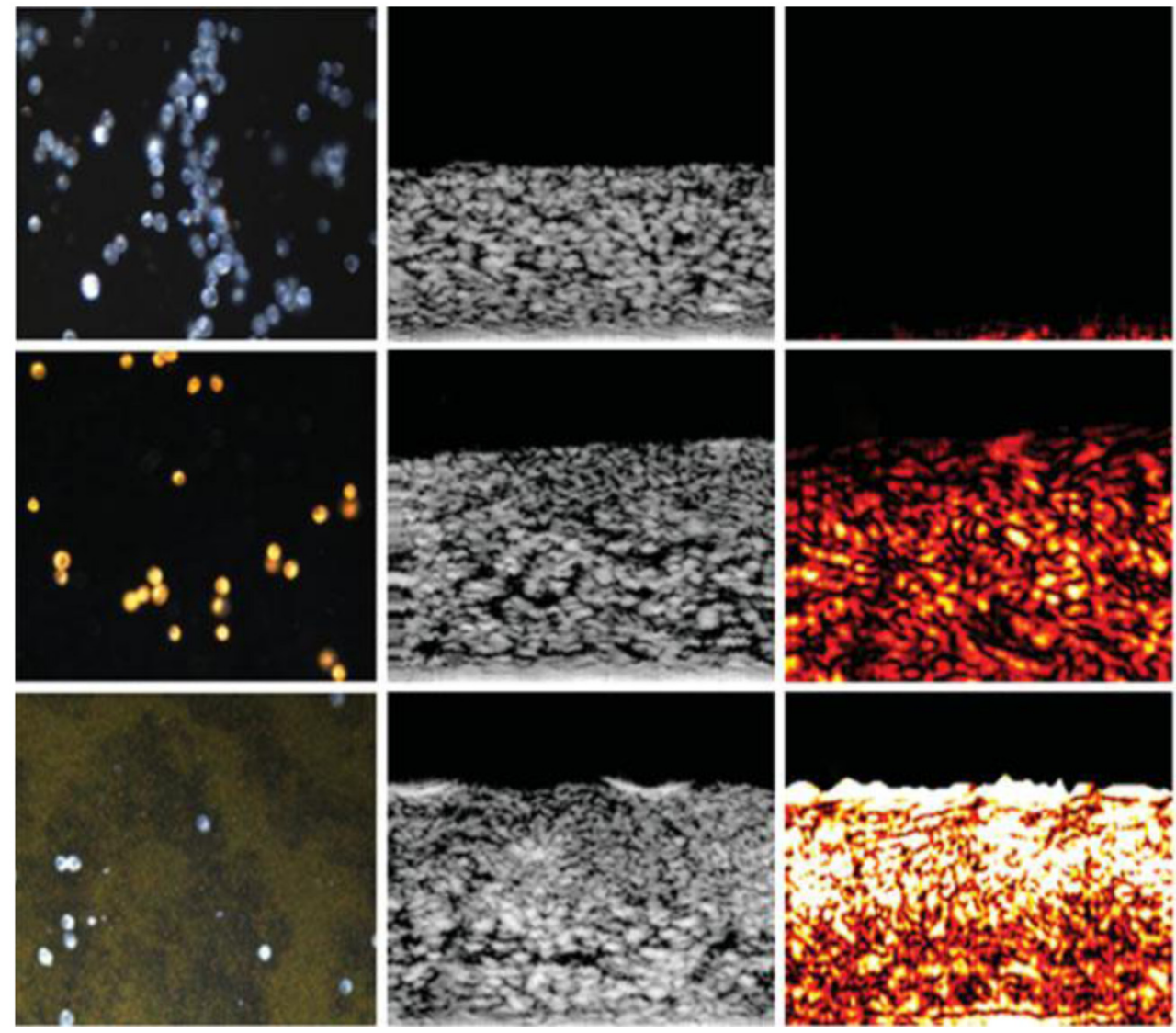

$\mathrm{Gd}^{3+}$ ions have a large spin magnetic moment per atom $(7 \mu \mathrm{B})$ as compared to that of $\mathrm{Fe}^{3+}$ ion $(5 \mu \mathrm{B})$ [93-95].

\section{Localizing Nanoparticle Concentrations and Hyperther- mia Imaging}

Nanoparticle based imaging is emerging as a multifunctional imaging technique to visulize tumor malignancies. Present time, optical fluorescence using Near-InfraredFluorochrome (NIRF) iron oxide-NIRF complexes have a unique place in multifunctional and multimodal probes [96107]. Recently, fluorescent labeled complexes of iron-oxide has opened the window of MRI imaging with near IRfluorescence and optical imaging as future clinical utility in intraoperative tumor discrimination from brain tissue [108, 109]. Gold, iodine and barium particles have been proven as potential X-ray absorbent CT contrast agents [110]. However, still their use as selective molecular or cell imaging CT contrast agents is a major challenge due to their nonspecificity [111]. There is a growing interest in development of gold particle as a site-specific, sensitive, tumor protein specific, easily concentrated or deposited locally in leaky tumor vasculature for optical coherence tomography (OCT), photoacoustic tomography and CT contrast imaging [112]. The pharamacokinetic and toxicity data suggested gold particles get cleared through hepatic pathway and remain harmless $\left(\mathrm{LD}_{50}=3.2 \mathrm{~g}\right.$ Au per $\mathrm{Kg}$ body weight $)$ as potential molecular imaging CT contrast agents [113]. Other applications are MRI and superconducting quantum

Fig. (3). Darkfield, ultrasound and photoacoustic images $(\lambda=\mathbf{5 3 2} \mathrm{nm}$ and $680 \mathrm{~nm})$ of control, targeted and non-targeted tissue phantoms by using DTTA thiol-functionalized gold NPs complexed with paramagnetic gadolinium or diamagnetic yttrium rare-earth ions . The darkfield images measure $440 \mu \mathrm{m}$ by $340 \mu \mathrm{m}$ field of view. The ultrasound and optoacoustic images measure $2 \mathrm{~mm}$ by $1.67 \mathrm{~mm}$. Reproduced with permission from reference [135]. 

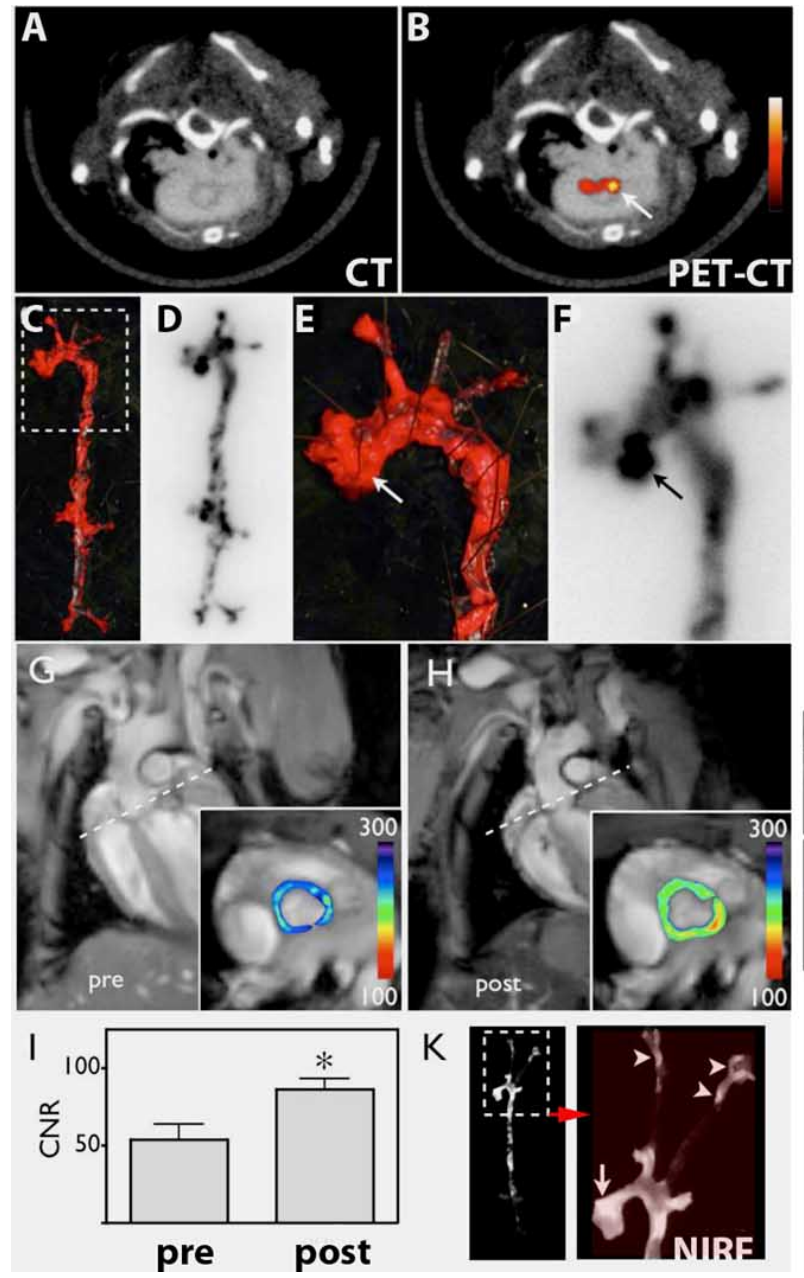
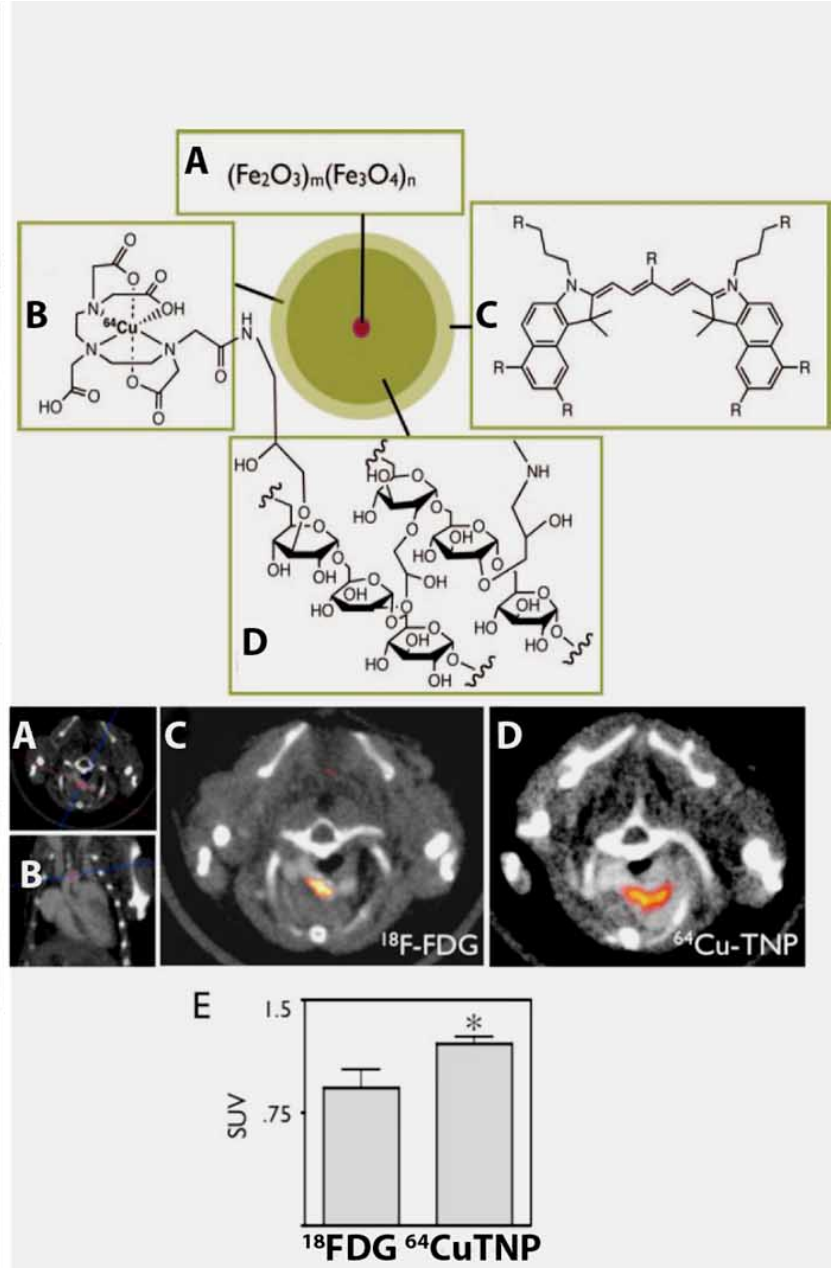

Fig. (4). 64Cu-trimodal nanoparticles distribute to atherosclerotic lesions. A and B, PET-CT shows enhancement of the posterior aortic root (arrow). C through F, Enface Oil Red O staining of the excised aorta depicts plaque-loaded vessel segments, which colocalize with areas of high $64 \mathrm{Cu}-\mathrm{TNP}$ uptake on autoradiography. $\mathbf{E}$ and $\mathbf{F}$, Zoomed image of the root and arch. Arrows depict a plaque-laden segment of the root with high activity, which corresponds to the in vivo signal seen in B. G through I, Preinjection and postinjection MRIs of the aortic root (inset). The dotted line in the long-axis views demonstrates slice orientation for short-axis root imaging. I, Signal intensity (pseudocolored with identical scaling for preinjection and postinjection image) decreased significantly after injection of $64 \mathrm{Cu}-\mathrm{TNP}$, which was quantified by calculation of the contrast-to-noise ratio (CNR). K, Near-infrared fluorescence reflectance imaging (NIRF) of excised aortas shows accumulation of the probe in plaques residing in the root (arrow), thoracic aorta, and carotid bifurcation (arrowheads), further corroborating the PET signal observed in these vascular territories. ${ }^{*} P \_0.01$.

(Top on right) $\mathrm{Cu}-64$ trimodal nanoparticle structure. Schematic view of the trimodality reporter $\mathrm{Cu}-64 \mathrm{TNP}$. A, Derivatization with the chelator DTPA allows attachment of radiotracer $64 \mathrm{Cu}$. B, Iron oxide core provides contrast in MRI (T2, T2*, or steady-state free-precession) sequences). C, Fluorochrome for fluorescence imaging, including fluorescence microscopy, flow cytometry, and fluorescence-mediated tomography. D, Crosslinked aminated polysaccharide coating provides biocompatibility, determines blood half-life, and provides linker for attachment of tracers and potentially affinity ligands. Reproduced with permission from reference [150].

MRI and superconducting quantum interference device (SQUID) to visualize the localized nanoparticles depending on their susceptibility and quantum interference characteristics [114-116].

\section{Temperature Imaging by MRI in Hyperthermia}

MRI is still the choice of both anatomical and quantitative thermometric information due to its advantage of noninvasive, non-radioactive and reliable temperature dependent MR phase behavior. The changes in local magnetic field $\left(B_{0}\right)$ and Larmor frequency cause a phase difference $\Delta \varphi$ and temperature difference $(\Delta \mathrm{T})$ in acquired MR phase image. The phase shift thermometry can be represented as:
$\Delta \varphi=\gamma . \alpha . \mathrm{B}_{0} \Delta \mathrm{T} . \mathrm{TE}$

Eq. 9

Where $\gamma$ is gyromagnetic ratio, $\alpha$ the temperature coefficient, TE is echo time.

From a physics standpoint, the application of magnetic gradients $G(x, y, z)$ superimposed over $B_{o}$ following three space coordinates $(\mathrm{x}, \mathrm{y}, \mathrm{z})$ displays 3 dimensional sets of coordinates $(x, y, z)$ of protons after each proton's oscillation at a different frequency due to release of different $B_{1}$ induced magnetic field strengths at different locations. This distribution also causes a phase difference in induced B1 magnetic fields that is displayed as temperature map. The overall MRI signal with temperature weighting can be given as: 
$\mathrm{S}(\mathrm{t})=\int \cdot \mathrm{M}_{(\mathrm{x}, \mathrm{y}, \mathrm{z})} \mathrm{e}^{\mathrm{i} /(\mathrm{Gx}+\mathrm{Gy}+\mathrm{Gz}) \mathrm{t}} \cdot \mathrm{d}_{\mathrm{x}} \cdot \mathrm{d}_{\mathrm{y}} \cdot \mathrm{d}_{\mathrm{z}} \quad$ Eq. 10

Where $\mathrm{S}(\mathrm{t})$ is MRI signal collected at an MRI antenna, $M_{(x, y, z)}$ is the magnetization intensity at a specific point including magnitude $i$ and phase $\varphi$, at that point. The term $\gamma\left(\mathrm{G}_{\mathrm{x}}+\mathrm{G}_{\mathrm{y}}+\mathrm{G}_{\mathrm{z}}\right) \mathrm{t}$ is phase $\varphi$.

The temperature change will be phase difference as:

$$
\mathrm{T} 1-\mathrm{T} 2 \simeq \Delta \varphi_{2-1}=\mathrm{k} . \Delta \mathrm{T}\left(\mathrm{t}_{\mathrm{e} 2}-\mathrm{t}_{\mathrm{e} 2}\right) \quad \text { Eq. } 11
$$

Where the $\Delta \mathrm{T}$ is temperature difference and $\left(\mathrm{t}_{\mathrm{e} 2}-\mathrm{t}_{\mathrm{e} 2}\right)$ is difference in first and second echoes.

Under well controlled conditions, the phase can represent the temperature variation. Using this application, phase maps at different tissue temperatures can generate phase difference MRI maps as temperature distribution map as shown in Equations 6 and 7. Antibodies, peptides and other target molecules bound with magnetic contrast agents interact the target and generate local magnetic perturbation with enhanced proton relaxation. The increased proton relaxation offers an excellent detectable Magnetic Resonance Imaging signal. So, nanoparticles act as an MRI contrast. Reports are now available on various types of molecular and nanoparticle iron-oxide in a broad range of MRI applications to enhance image contrast $[117,118]$. The nanoparticle concentration, quantity, and form of the nanoparticle as molecular, oxide or naked particle in tissue play a role as target conjugated contrast in both in vivo and in vitro imaging [119]. In this, image subtraction approach is suitable to increase detection sensitivity as a result of a perturbed local field by nanoparticles in the optimized range $2 \mu \mathrm{g} \mathrm{Fe} / \mathrm{gm}$ tissue [108]. Another approach of saturation magnetization of a contrast agent in the applied field is also crucial to enhance sensitivity threshold [120]. A concept is emerging of measuring neuronal currents by nanoparticle enhanced phase-shift MRI using variable magnetic field distribution at nano scale. Recent reports suggested the possibility of a nanoparticle enhanced detection limit of 1.7 nanoTesla to local field inhomogeneities in $8 \mathrm{~mm}^{3}$ voxel, using gradient-recalled echo planar imaging (EPI) and a better detection limit of up to 200 picoTesla using single-shot spin-echo (SE) echo planar sequence [121]. Another group of researchers showed the detection threshold of $1.1 \times 10^{-10} \mathrm{~T}$ in $2 \mathrm{~mm} \times 3 \mathrm{~mm} \times 3 \mathrm{~mm}$ $\left(18 \mathrm{~mm}^{3}\right)$ voxel [122]. The sensitivity of the spin echo-echo planar (SE-EPI) technique was reported to generate a detection limit up to 36 picoGrams $\mathrm{Fe}_{2} \mathrm{O}_{3}$ magnetic nanoparticles deposited in $100 \mathrm{~nm}$ size within tissue voxel size $2 \mathrm{~mm} \times 2$ $\mathrm{mm} \times 2 \mathrm{~mm}\left(8 \mathrm{~mm}^{3}\right)$ with a conservative sensitivity limit of $3 \times 10^{-10} \mathrm{~T}$ [123]. Recently progress is reported using an ultra-low field MRI may provide greater sensitivity using ferromagnetic nanoparticles to generate sensitivity to changes of less than $50 \mathrm{pT}$ in voxel [124]. However, it requires the consideration of imaging localized nanoparticle concentrations independent of tissue depth and limited to the proton spins within the tissue area with distributed nanoparticles. The MRI measures the dephasing effect of nanoparticle fields on spin population [125-127]. An additional limit is that a MRI cannot measure the nanoparticle induced fields as a distance.

\section{New Approaches of Nanoparticles in Tumor Hyperther- mia Killing}

Magnetic nanoparticles have found utility in many biological applications, including imaging, cancer therapy, drug delivery, sensing and hyperthermia for tumor therapy. In general, hyperthermia raises the tissue temperature between 41.5 - 46 degrees Celsius to kill cancerous cells while preserving the normal cells. Several nanoparticles such as gold, zinc, gadolinium, lanthanum, and calcium have emerged as potential hyperthermia agents. Recently, new composite materials such as $\mathrm{Mn}-\mathrm{Zn}-\mathrm{Fe}, \mathrm{Co}-\mathrm{Gd}-\mathrm{Zn}$ and $\mathrm{Zn}-\mathrm{Gd}-\mathrm{Fe}$ nanoparticles with stable magnetic behavior have replaced magnetic oxides for use in hyperthermia at our lab. These composites generated sufficient heat at room temperature and stop heating at the Curie temperature $T_{c}$ of the respective nanoparticle system.

\section{Gold Nanoparticles}

Gold nanoparticles (AuNP) killing the cancer cells was first reported [45]. However, after injecting gold particles in animals and irradiation them by $250 \mathrm{kV}$, X-rays caused tumor shrinkage and enhanced survival rate by four fold [128]. Gold nanoparticles are easily functionalized by thiol derivatives and open multimodal imaging perspectives. To design a potential MRI contrast agent, nanocrystals coated with $\mathrm{Gd}^{3+}$ chelates present the advantage of a generating a rigid core that minimizes internal degrees of freedom. Another interesting aspect is the high electron density of these heavy-metal objects, promising gold NPs as agents for X-ray heating and CT imaging shown in Fig. (2). Multimodal imaging techniques have emerged using MRI-CT hybrid imaging and gold nanoparticles have unique role to answer for this multimodal art. The technique depends on the fact that gold NPs show intrinsic magnetization of $\mathrm{Au}$ in thiol-capped gold NPs with a permanent magnetism at room temperature. The major challenge was localization of gold particles because of vascular leakage in the tumor but maximized particles entry in the tumor. Still, there are ample potential evidences in favor of gold enhanced x-ray hyperthermia in tumor treatment by killing [129]. Other reported application of gold particles in nanomedicine is its promise in radiotherapy of cancer [130]. The Au-198 ( $\beta_{\max }=0.96 \mathrm{MeV} ; \mathrm{t} / 2=2.7$ days $)$ and $\mathrm{Au}-199\left(\beta_{\max }=0.46 \mathrm{MeV} ; \mathrm{t} / 2=3.14\right.$ days $)$ make them suitable in radiotherapy. In addition, gold particles display gamma emissions for dosimetry and pharmacokinetic studies. Therapeutic agents derived from gold particles provide a higher radioactivity dose to tumor sites. Furthermore, tumorspecific nanotherapeutic agents as a nanoparticle while tagged with peptides selective to receptors and overexpressed by tumor concentration offer another advantage. Recently, gold nanoradioisotopes encapsulated within a nanocomposite device were reported as vehicles to transport radioactive particles to tumor sites [131]. In this approach, particle size and number play a significant role such as nanocomposites made of monodisperse hybrid radioactive gold nanoparticles immobilized by dendritic polyamidoamine matrix prepared by reaction of polymer and tetrachloroaurate $\mathrm{HAuCl}_{4}$ solution. The salt formation between these solutions ensured the effective encapsulation of gold within the matrix using neutron irradiation in mice B 16 melanoma, prostate DU 145, human KB squamous cell carcinoma xenograft models. The property of polymer with $\beta$ emitting Au-198 enriched nano-device proved useful in tumor therapy [132]. Moreover, the polymer enhances the stealthiness of magnetic nanoparticles by preventing macrophage recognition of particles as less toxic and resisting oxidation to make them 
valuable in multifunctional hyperthermia and imaging modalities [133]. Another issue in tumor treatment is delivery of chemo-, gene-, radiotherapeutic agents within gold nanoparticles. It becomes effective as a tumor killing and targeted delivery tool. Authors reported the possible use of thiol derivative DTTA13 chelate (called Dt) as the protective agent for the Au NPs. Gold Dt-coated NPs (DtNP) are synthesized using different $\mathrm{HAuCl} / \mathrm{Dt}$ ratios. DtNPs can be complexed with gadolinium(III) and yttrium(III) by mixing solutions of DtNPs with a slight excess of aqueous solutions of $\mathrm{LnCl}_{3}$, (Ln)Gd, Y. AuDTDTPA-Gd can be applied as a radiosensitizer for radiotherapy using injection of gold nanoparticles (with a diameter of $1.9 \mathrm{~nm}$ with surface composition)

Au-DTDTPA-Gd nanoparticles are based on DTDTPA ligand $3 \mathrm{COOH}$ moieties as anchoring sites. Gold nanostructures induce the destruction of cancerous cells after activation with an external physical stimulus (electromagnetic radiation in X-ray and near-infrared spectral domains, the development of nanoparticles for targeted diagnosis and therapy can be envisaged with Au-DTDTPA-Gd nanoparticles. New developments are expected in gold particles in NIRPAI, OCT, US imaging as illustrated in Fig. (3).

\section{Zinc-Gd Composites}

These multicoponent particles are made of $\mathrm{Zn}_{\mathrm{x}} \mathrm{Mn}_{(1-}$ ${ }_{x)} \mathrm{Fe}_{3} \mathrm{O}_{4}$ and $\mathrm{Mn}_{\mathrm{x}} \mathrm{Zn}_{\mathrm{x}} \mathrm{Gd}_{\mathrm{x}} \mathrm{Fe}_{(2-\mathrm{x})} \mathrm{O}_{4}$ composites synthesized by physical and chemical co-precipitation methods. These particles displayed the increased tissue temperature and hyperthermia nature [134]. Additionally particles in the form of $\mathrm{Ni}_{(1-\mathrm{x})} \mathrm{Cr}_{\mathrm{x}}$ were also formed [135]. These particles may be encapsulated in thermo-sensitive polymer that dissolves when melted. The magnetic $\mathrm{Mn}-\mathrm{Zn}$ ferrite and Gd substituted $\mathrm{Mn}-\mathrm{Zn}$ ferrite particles synthesized by the chemical coprecipitation method exhibited a specific behavior applicable in hyperthermia.

\section{Gadolinium Complex}

Paramagnetic gadolinium offers the excellent detection limit using contrast injection of $15 \mathrm{gm} / \mathrm{gm}$ tissue in clinical MR imaging but causes renal toxicity and skin changes [136]. In our lab, gadolinium toxicity was tested on excised skin using $500 \mathrm{MHz}$ MR microscopy. We proposed that two Gadolinium binding properties are responsible for imaging tissue contrast: 1.Gadolinium binding with tissue proteins (protein conformation) such as collagen targeted or albumin targeted gadolinium contrast agents; 2. Gadolinium coordination ligand DOTA complexes [137]. These two factors enhance MR relaxivity rate linearly with gadolinium ion (M) as:

$$
r_{1}=\frac{\Delta\left(1 / T_{1}\right)}{[\mathrm{M}]}
$$

where $r_{1}=1 / T_{1}$, and gadolinium concentration is [M]. The relaxivity also depends on physical factors related with protein conformation, gadolinium-water interactions in hyperthermia such as inner sphere relaxivity, rotational diffusion, electronic relaxation and water exchange [137, 138]. Nanosized Gd substituted Mn-Zn ferrite particles have been synthesized by a chemical coprecipitation method. These particles were mostly soft-magnetic Gd substituted Mn-Zn Ferrite nanoparticles using chemical co-precipitation [139].
Investigators observed an increase in the pyromagnetic coefficient $(\mathrm{HTM}) /(\partial \partial)$ of the resultant particles. The increase in the pyromagnetic coefficient is desirable because it results in a steeper slope of the magnetization $\mathrm{v} / \mathrm{s}$ temperature plot which in turn ensures that the magnetization decreases rapidly as the temperature approaches the Curie temperature.

\section{Lanthanum Complex}

The Silica-Coated Lanthanum-Strontium Manganite Particles were prepared suited for hyperthermia. The corecomprising LaSr-manganites with different stoichiometries, ranging from $\mathrm{La}_{0.5} \mathrm{Sr}_{0.5} \mathrm{MnO}_{3+\delta}$ to $\mathrm{LaMnO}_{3+\delta}$, were synthesized as silica-coated magnetic particles with designable Curie temperature, offering a wide range of possibilities of adapting the material to practical instrumental setups in drug delivery and hyperthermia treatments [140]. The relationship was based on temperature dependence of the proton chemical shift of water $\leq 0.01 \mathrm{ppm} /{ }^{\circ} \mathrm{C}$ at $\leq 0.7 \mathrm{~Hz}$ at $1.5 \mathrm{~T}$ for $1{ }^{\circ} \mathrm{C}$ temperature change using lanthanide complexes [141].

\section{Calcium Complexes}

Malignant Hyperthermia (MH) is a hypermetabolic syndrome that results from the altered control of sarcoplasmic reticulum (SR) $\mathrm{Ca}^{2+}$ release. Recent study established the imaging of cytosolic $\left[\mathrm{Ca}^{2+}\right]\left(\left[\mathrm{Ca}^{2+}\right]_{c}\right)$ in single cells grown from human skeletal muscle biopsies and in $\mathrm{H} 9 \mathrm{c} 2$ myotubes in response to a low dose of halothane on the cells derived from $\mathrm{MH}$ susceptible patients. The $\mathrm{Ca}^{2+}$ imaging in single cells is a promising candidate for the development of a new diagnostic and hyperthermia procedure of MH [142-145].

\section{Copper Complexes}

The sensitivity, diagnostic accuracy, absolute concentration measurement, specificity of molecular label to the tissue disease entity will remain a open issue to more investigations and explorations. Safety of using nanoparticles, optimal dose administration within safe limits with risk free hyperthermia mapping applications is still an open controversy. It will require extensive research to make these nanoparticles useful as hyperthermia modality.

\section{Nanoparticles in Hyperthermia Monitoring by Protein Targeted Imaging: New Development}

Use of nanoparticles has emerged for hyperthermia bioimaging by multimodal and multifunctional molecular complexes based on protein targeting. Several proteins such as albumin, ferritin, collagen, integrins, fibrins, heat shock proteins, enzymes and antibodies act as imaging targets. The targeted locations generate biophysical signal measured by different imaging modalities. We have focused on MR thermometry, photoacuastic mapping of different tumor locations. Recent improvements in optical imaging techniques now allow these microdomains to be visualized such as single channel calcium fluorescence transients (SCCaFTs), providing information about channel properties to monitor the activity and localization of microdomain calcium complexes [146]. Other emerging possibilities are MR thermal mapping by gadolinium-ferrite complexed with $\mathrm{Zn}$ or $\mathrm{Co}$ or perfluorocarbons, integrins, fibrins, and monoclonal antibody labeled nanoparticles $[147,148]$. Recently remarkable progress was reported in real-time monitoring of thermal ther- 
apy and ablation using multimodal imaging techniques [149].

${ }^{64} \mathrm{Cu}$-polymer encaged iron oxide nanoparticle hybrid synthesis seems future of different nanoelement applications such as copper, gold, silver, iron, cadmium, manganese, zinc, iodine, fluorine, phosphorus etc. Paramagnetic rare earth elements such as lanthanum, gadolinium have potential in making nanocomposites encaged with polymer coats and further can be tagged with specific antibodies. Recently ${ }^{64} \mathrm{Cu}$-TNP nanoparticle MION with dextran coating was crosslinked in first step with epichlorin hydrin, aminated and labeled with near infrared fluorochrome Vivotag-680 (VT680, VisEn Medical, Woburn, MA) in ratio of VT680 per nanoparticle ( 5 dye moieties/NP) for bioimaging applications [150].

In second step, nanocomplex gets mixed with excess dianhydride DTPA (Sigma, St. Louis, MO) for 2 hours in $0.15 \mathrm{M}$ borate buffer, $\mathrm{pH} 9.4$ at room temperature in phosphate buffer $\left(\mathrm{pH}\right.$ 7.4) for the preparation of ${ }^{64} \mathrm{Cu}-\mathrm{DTPA}-\mathrm{NP}$ or ${ }^{64} \mathrm{Cu}$-TNP, non-radioactive copper salts [150].

Using same strategy, we modified synthesis of nanoparticles further as following:

1. One hundred $\mu \mathrm{g}$ DTPA-NP labeling with ${ }^{64} \mathrm{CuCl}_{2}$ (IsoTrace, Toronto, Canada) or $190 \mathrm{MBq}{ }^{64} \mathrm{Cu}$, in ammonium acetate buffer $(180 \mu \mathrm{L}, 0.45 \mathrm{M}, \mathrm{pH} 5.5)$;

2. After $25 \mathrm{~min}$ of incubation at $96^{\circ} \mathrm{C}$, content centrifugation and washing three times to get pure ${ }^{64} \mathrm{Cu}$-TNP to re-dissolve in $400 \mu \mathrm{L} \mathrm{PBS}$;

3. Routine analysis of aliquots by HPLC with a $\mathrm{C}_{18}$ column, multi-wavelength detector and a flow-through gamma-detector. The specific activity of ${ }^{64} \mathrm{Cu}$-TNP was $1 \mathrm{mCi}$ per $0.1 \mathrm{mg}$ Fe of NP (corresponding to approximately $300 \mu \mathrm{Ci} /$ mouse or $1.5 \mathrm{mg} \mathrm{Fe} / \mathrm{kg}$ bodyweight);

4. The average diameter measurement of the NP was 20 $\mathrm{nm}$ by laser light scattering.

Such 64Cu-TNP hybrid approach can give opportunity to visualize the odd numbered nuclei (MRI), radiotags (PET,
SPECT), photons(CT), acoustic waves(US, PTI), bioluminescence or photophosphoresence (FTI, OCT, NIRF) as trimodal imaging of tumor.

The emergence of a newer class of nanoparticles as contrast agents have offered the localized tumor molecular imaging based monitoring of tumor hyperthermia and molecular mapping responsible for thermal heating of a tumor as represented in Table 3. However, multimodal and multifunctional approaches of hyperthermia monitoring and thermal mapping are still in their infancy to use them in routine [151]. The present growing interest of thermal mapping and hyperthermia monitoring is to achieve a rapid thermotherapy heating effect over focused tumor areas accurately by molecular imaging techniques.

\section{Effective Hyperthermia and Radiosensitizers Combined with Hypoxia Chemotherapy}

Radiosensitizers such as radiolabeled nitroimidazoles were reported with chemotherapy to kill tumor and monitor the effect of hyperthermia and hypoxia by MRI, PET, CT, SPECT [152-158]. Recently, technical advances in the field of multimodal multifunctional use of nanoparticles, now radiolabeled $\left[{ }^{18} \mathrm{~F}\right]$ MISO, $\left[{ }^{18} \mathrm{~F}\right]$ FETNIM, EB3, EF5 complexes were reported sensitive to hypoxia and measuring the response of hyperthermia [159, 160]. The art of nanoparticles in hyperthermia is growing technical development focused on thermal behavior and particle chemical characteristics such as magnetic polymersomes, nickel ferrite [161167]. Real time adaptive control algorithms are reported as robust tools of hyperthermia treatment in cancer [168-176].

\section{CONCLUSION}

The hyperthermia with use of magnetoparticle nanotechnology is state of the art in multimodal hyperthermia imaging and treatment of tumors. New techniques are emerging for synthesis, targeting tumor and energy deposition characteristics of nanoparticles in tissue. The physical principles of hybrid thermal mapping of tumors by MRI, CT, optical methods and imaging the nanoparticle concentrations in tissue may provide better understanding of hyperthermia and tissue temperature distribution. Recently, emerging biomedi-

Table 3. Potential Newer Nanoparticles Used in Thermal Mapping and Hyperthermia Monitoring. Different Nanoparticle Composites are Shown with their Use in Thermal Mapping Technique and Possible Use in Hyperthermia Monitoring. The Potential Nanoparticles in Hyperthermia Use are Shown with + Plus Sign for Routine Use +++, Research Use ++, Infancy State + or not Established - at Present

\begin{tabular}{|l|l|l|}
\hline Nanoparticles & Thermal mapping & Hyperthermia \\
\hline \hline Zinc-Gadolinium-Ferrite & MRI, CT & + \\
\hline Gold-Ferrite & MRI, CT & ++ \\
\hline Gadolinium-Ferrite & MRI, CT & +++ \\
\hline Lanthanum-Ferrite & MRI & + \\
\hline Calcium & Optical, Molecular & + \\
\hline Gd-Mn-Zn-Ferrite & MRI, CT & +++ \\
\hline Mn-Gd-Ce & MRI & -- \\
\hline La-Sr-Mn & MRI & -- \\
\hline Nanoparticulate agents & MRI & -- \\
\hline
\end{tabular}


cal applications of a newer class of composite nanoparticles in hyperthermia paved the way of multimodal imaging such as nanoparticle based MRI and CT. The behavior of Mn-Zn ferrite, gold, copper and $\mathrm{Gd}$ substituted $\mathrm{Mn}-\mathrm{Zn}$ ferrite nanoparticles is highlighted as dependent on $\mathrm{Gd}^{3+}$ ion proportions in nanoparticles with an increase in the net moment at Curie temperature. The $\mathrm{Mn}_{0.5} \cdot \mathrm{Zn}_{0.5}$. ferrite, gold, copper nanomagnetic particles behavior of ferromagnetic to paramagnetic transition at a specific temperature range may be significant in various hyperthermia or hypoxia mapping applications. Newer applications of gold, zinc, lanthanum and calcium in both hyperthermia and temperature mapping are in their infancy or growing in the research stage. More effective methods of combined nanoperticles with radiosensitizers and chemotherapeutic drugs are emerging in oncotheradiagnosis.

\section{DISCLOSURE}

Major portion of this manuscript included in this article has been previously published in JOURNAL OF NANOPARTICLE RESEARCH Volume 11, Number 3, 671-689, DOI: 10.1007/s11051-008-9548-z. Here it is presented extended version of the work done on nanoparticles in hyperthermia mapping and cancer therapy applications.

\section{REFERENCES}

[1] Harrison GG, Saunders SJ, Biebuyck JF, et al. Anaesthetic-induced malignant hyperpyrexia and a method for its prediction. $\mathrm{Br} \mathrm{J}$ Anaesth 1969; 41: 844-55.

[2] Cherukuri P, Curley SA.Use of nanoparticles for targeted, noninvasive thermal destruction of malignant cells. Methods Mol Biol 2010; 624: 359-73.

[3] Bellizzi G, Bucci OM. On the optimal choice of the exposure conditions and the nanoparticle features in magnetic nanoparticle hyperthermia. Int J Hyperthermia 2010; 26(4): 389-403.

[4] Li Z, Kawashita M, Araki N, Mitsumori M, Hiraoka M, Doi M. Preparation of magnetic iron oxide nanoparticles for hyperthermia of cancer in a $\mathrm{FeCl} 2-\mathrm{NaNO} 3-\mathrm{NaOH}$ aqueous system. J Biomater Appl 2010; [Epub ahead of print].

[5] Cantillon-Murphy P, Wald LL, Adalsteinsson E, Zahn M. Heating in the MRI environment due to superparamagnetic fluid suspensions in a rotating magnetic field. J Magn Magn Mater 2010; 322(6):727-33.

[6] Ankamwar B, Lai TC, Huang JH, et al. Biocompatibility of $\mathrm{Fe}(3) \mathrm{O}(4)$ nanoparticles evaluated by in vitro cytotoxicity assays using normal, glia and breast cancer cells. Nanotechnology 2010; 21(7): $75-102$.

[7] Alexiou C, Tietze R, Schreiber E, Lyer S. Nanomedicine: Magnetic nanoparticles for drug delivery and hyperthermia - new chances for cancer therapy. Bundesgesundheitsblatt Gesundheitsforschung Gesundheitsschutz 2010; 53(8):839-45.

[8] Chen Y, Chen BA. Application and development of magnetic ironoxide nanoparticles in tumor-targeted therapy. Ai Zheng 2010; 29(1): 118-22.

[9] Sharma R, Chen CJ. Newer nanoparticles in hyperthermia treatment and thermometry. J Nanopart Res 2009; 11(3): 671-89.

[10] Wust P, Hildebrandt B, Sreenivasa G, et al. Hyperthermia in combined treatment of cancer. Lancet Oncol 2002; 3: 487-97.

[11] Minamimura T, Sato H, Kasaoka S, et al. Tumour regression by inductive hyperthermia combined with hepatic embolization using dextran magnetite incorporated microspheres in rats. Int J Oncol 2000; $16: 1153-8$

[12] Terentyuk GS, Maslyakova GN, Suleymanova LV, et al. Laserinduced tissue hyperthermia mediated by gold nanoparticles: toward cancer phototherapy. J Biomed Opt 2009; 14(2): 021016.

[13] von Maltzahn G, Park JH, Agrawal A, et al. Computationally guided photothermal tumor therapy using long-circulating gold nanorod antennas. Cancer Res 2009; 69(9): 3892-900.

[14] Han B, Hanson WL, Bensalah K, Tuncel A, Stern JM, Cadeddu JA. Development of quantum dot-mediated fluorescence thermometry for thermal therapies. Ann Biomed Eng 2009; 37(6): 1230-9.
[15] Wilhelm C, Fortin JP, Gazeau F. Tumour cell toxicity of intracellular hyperthermia mediated by magnetic nanoparticles. J Nanosci Nanotechnol 2007; 7(8): 2933-7.

[16] Sharma HS, Sharma A, Hussain S, Schlager J, Sjöquist PO, Muresanu D. A new antioxidant compound H-290/51 attenuates nanoparticle induced neurotoxicity and enhances neurorepair in hyperthermia. Acta Neurochir Suppl 2010; 106: 351-7.

[17] Cherukuri P, Glazer ES, Curley SA. Targeted hyperthermia using metal nanoparticles. Adv Drug Deliv Rev 2010; 62(3): 339-45.

[18] Wen D. Intracellular hyperthermia: Nanobubbles and their biomedical applications. Int J Hyperthermia 2009; 25(7): 533-41.

[19] Jordan A, Maier-Hauff K. Magnetic nanoparticles for intracranial thermotherapy. J Nanosci Nanotechnol. 2007; 7(12): 4604-6.

[20] Pradhan P, Giri J, Rieken F, et al. Targeted temperature sensitive magnetic liposomes for thermo-chemotherapy. J Control Release 2010; 142(1): 108-21.

[21] Le Renard PE, Jordan O, Faes A, et al. The in vivo performance of magnetic particle-loaded injectable, in situ gelling, carriers for the delivery of local hyperthermia. Biomaterials 2010; 31(4): 691-705.

[22] Meenach SA, Hilt JZ, Anderson KW. Poly(ethylene glycol)-based magnetic hydrogel nanocomposites for hyperthermia cancer therapy. Acta Biomater 2010; 6(3): 1039-46.

[23] Purushotham S, Ramanujan RV. Thermoresponsive magnetic composite nanomaterials for multimodal cancer therapy. Acta Biomater 2010; 6(2): 502-10.

[24] Purushotham S, Chang PE, Rumpel H, et al. Thermoresponsive core-shell magnetic nanoparticles for combined modalities of cancer therapy. Nanotechnology 2009; 20(30): 305101.

[25] Kaman O, Pollert E, Veverka P, et al. Silica encapsulated manganese perovskite nanoparticles for magnetically induced hyperthermia without the risk of overheating. Nanotechnology 2009; 20(27): 2756-10.

[26] Prasad NK, Rathinasamy K, Panda D, Bahadur D. TC-tuned biocompatible suspension of $\mathrm{La} 0.73 \mathrm{Sr} 0.27 \mathrm{MnO} 3$ for magnetic hyperthermia. J Biomed Mater Res B Appl Biomater 2008; 85(2): 40916.

[27] Thiesen B, Jordan A. Clinical applications of magnetic nanoparticles for hyperthermia. Int J Hyperthermia 2008; 24(6): 467-74.

[28] Latorre M, Rinaldi C. Applications of magnetic nanoparticles in medicine: magnetic fluid hyperthermia. P R Health Sci J 2009; 28(3): 227-38.

[29] Curley SA, Cherukuri P, Briggs K, et al. Noninvasive radiofrequency field-induced hyperthermic cytotoxicity in human cancer cells using cetuximab-targeted gold nanoparticles. J Exp Ther Oncol 2008; 7(4): 313-26.

[30] Cheong SK, Krishnan S, Cho SH. Modeling of plasmonic heating from individual gold nanoshells for near-infrared laser-induced thermal therapy. Med Phys 2009; 36(10): 4664-71.

[31] Martinez-Boubeta C, Balcells L, Cristòfol R, et al. Self-assembled multifunctional $\mathrm{Fe} / \mathrm{MgO}$ nanospheres for magnetic resonance imaging and hyperthermia. Nanomedicine 2010; 6(2): 362-370.

[32] Nam J, Won N, Jin H, Chung H, Kim S. pH-Induced aggregation of gold nanoparticles for photothermal cancer therapy. J Am Chem Soc 2009; 131(38): 13639-45.

[33] Salvador-Morales C, Gao W, Ghatalia P, et al. Multifunctional nanoparticles for prostate cancer therapy. Expert Rev Anticancer Ther 2009; 9(2): 211-21.

[34] Tseng HY, Lee GB, Lee CY, Shih YH, Lin XZ. Localised heating of tumours utilising injectable magnetic nanoparticles for hyperthermia cancer therapy. IET Nanobiotechnol 2009; 3(2): 46-54.

[35] Hadjipanayis CG, Bonder MJ, Balakrishnan S, Wang X, Mao H, Hadjipanayis GC. Metellic iron nanoparticles for MRI contract enhancement and local hyperthermia. Small 2008; 4(11): 1925-9.

[36] Lal S, Clare SE, Halas NJ. Nanoshell-enabled photothermal cancer therapy: impending clinical impact. Acc Chem Res 2008; 41(12): 1842-51.

[37] Jin H, Kang KA. Application of novel metal nanoparticles as optical/thermal agents in optical mammography and hyperthermic treatment for breast cancer. Adv Exp Med Biol 2007; 599: 45-52.

[38] Skrabalak SE, Au L, Lu X, Li X, Xia Y. Gold nanocages for cancer detection and treatment. Nanomedicine (Lond) 2007; 2(5): 657-68.

[39] Van der Zee J. Heating the patient: a promising approach? Ann Oncol 2002; 13: 1173-

[40] Wang ZY, Song J, Zhang DS. Nanosized $\mathrm{As}_{2} \mathrm{O}_{3} / \mathrm{Fe}_{2} \mathrm{O}_{3}$ complexes combined with magnetic fluid hyperthermia selectively target liver cancer cells. World J Gastroenterol 2009; 15(24): 2995-3002.

[41] Ciofani G, Riggio C, Raffa V, Menciassi A, Cuschieri A. A bimodal approach against cancer: magnetic alginate nanoparticles for combined chemotherapy and hyperthermia. Med Hypotheses 2009; 73(1): 80-2. 
[42] Melnikov OV, Gorbenko OY, Markelova MN, et al. Ag-doped manganite nanoparticles: new materials for temperature-controlled medical hyperthermia. J Biomed Mater Res A 2009; 91(4): 104855.

[43] Liu C, Mi CC, Li BQ. Energy absorption of gold nanoshells in hyperthermia therapy. IEEE Trans Nanobiosci 2008; 7(3): 206-14.

[44] Huang X, Qian W, El-Sayed IH, El-Sayed MA. The potential use of the enhanced nonlinear properties of gold nanospheres in photothermal cancer therapy. Lasers Surg Med 2007; 39(9): 747-53.

[45] Han S, Lin J, Zhou F, Vellanoweth RL. Oligonucleotide-capped gold nanoparticles for improved atomic force microscopic imaging and enhanced selectivity in polynucleotide detection. Biochem Biophys Res Commun 2000; 279(1): 265-9.

[46] Heinfeld JF, Slatkin DN, Focella TM, Smilowitz HM. Gold nanoparticles: a new X-ray contrast agent. Br J Radiol 2006; 79: 248-53.

[47] Naruse S, Higuchi T, Horikawa Y, Tanaka C. Radiofrequency hyperthermia with successive monitoring of its effects on tumors using NMR spectroscopy. Proc Natl Acad Sci USA 1986; 83(21): 8343-7.

[48] Zhu D, Lu W, Weng Y, Cui H, Luo Q. Monitoring thermal-induced changes in tumor blood flow and microvessels with laser speckle contrast imaging. Appl Opt 2007; 46(10):1911-7.

[49] Ito A, Tanaka K, Kondo K, et al. Tumor regression by combined immunotherapy and hyperthermia using magnetic nanoparticles in an experimental subcutaneous murine melanoma. Cancer Sci 2003; 94 (3): 308-13.

[50] Ghosh S, Dutta S, Gomes E, et al. Increased heating efficiency and selective thermal ablation of malignant tissue with DNA-encased multiwalled carbon nanotubes. ACS Nano 2009; 3(9): 2667-73.

[51] Sharma R. Nanoparticles that facilitate imaging of biological tissue and methods of forming the same. US Patent 200900220434 Sept 3.

[52] Oh P, Borgström P, Witkiewicz H, et al. Live dynamic imaging of caveolae pumping targeted antibody rapidly and specifically across endothelium in the lung. Nat Biotechnol 2007; 25(3): 327-37.

[53] Gellermann J, Wlodarczyk W, Feussner A, et al. Methods and potentials of magnetic resonance imaging for monitoring radiofrequency hyperthermia in a hybrid system. Int J Hyperthermia 2005; 21: 497-513.

[54] Salloum M, Ma R, Zhu L. Enhancement in treatment planning for magnetic nanoparticle hyperthermia: optimization of the heat absorption pattern. Int J Hyperthermia 2009; 25(4): 309-21.

[55] Maswadi SM, Dodd SJ, Gao JH, Glickman RD. Temperature mapping of laser-induced hyperthermia in an ocular phantom using magnetic resonance thermography. J Biomed Opt 2004; 9(4):711-8.

[56] Heisterkamp J, vanHillegersberg R, Ijzermans JNM. Critical temperature and heating time for coagulation damage: Implications for interstitial laser coagulation (ILC) of tumors. Lasers Surg Med 1999; 25: 257-62.

[57] Lewin JS, Conell CF, Duerk JL, et al. Interactive MRI-guided radiofrequency interstitial thermal ablation of abdominal tumors: Clinical trial for evaluation of safety and feasibility. J Magn Reson Imaging 1998; 8: 40-47.

[58] Hiroka M, Mitsumori M, Hiroi N, et al. Development of RF and microwave heating equipment and clinical application to cancer treatment in japan. IEEE Trans Microw Theory Tech 2000; 48: 1789-99.

[59] McFerrin MB, Sontheimer H. Optical and MRI multifunctional nanoprobe for targeting gliomas. Neuron Glia Biol 2006; 2(1):3949.

[60] Baker I, Zeng Q, Li W, Sullivan CR. Heat deposition in iron oxide and iron nanoparticles for localized hyperthermia. J Appl Phys 2006; 99(8): 106.

[61] Pankhurst QA, Connolly J, Jones SK, Dobson J. Applications of magnetic nanoparticles in biomedicine. J Phys D: Appl Phys 2003; 36:167-81.

[62] Moroz P, Jones SK, Gray BN. Magnetically mediated hyperthermia: Current status and future directions. Int J Hyperthermia 2002; 18: $267-84$.

[63] Jordan A, Scholz R, Maier-Hauff K, et al. Presentation of a new magnetic field therapy system for the treatment of human solid tumors with magnetic fluid hyperthermia. J Magn Magn Mater 2001; 225(1): 118-26.

[64] Kong G, Braun RD, Dewhirst MW. Characterization of the effect of hyperthermia on nanoparticle extravasation from tumor vasculature. Cancer Res 2001; 61:3027.

[65] Fortin JP, Gazeau F, Wilhelm C. Intracellular heating of living cells through Néel relaxation of magnetic nanoparticles. Eur Biophys J 2008; 37(2): 223-8.
[66] Atsarkin VA, Levkin LV, Posvyanskiy VS, et al. Solution to the bioheat equation for hyperthermia with $\mathrm{La}(1-\mathrm{x}) \mathrm{Ag}(\mathrm{y}) \mathrm{MnO}(3-$ delta) nanoparticles: the effect of temperature autostabilization. Int $\mathrm{J} \mathrm{Hy}-$ perthermia 2009; 25(3): 240-7.

[67] Hergt R, Dutz S, Zeisberger M. Validity limits of the Néel relaxation model of magnetic nanoparticles for hyperthermia. Nanotechnology 2010; 21(1): 015706.

[68] Tanaka K, Ito K, Kobayashi $\mathrm{T}$, et al. Intratumoral injection of immature dendrite cells enhances antitumor effect of hyperthermia using magnetic nanoparticles. Int J Cancer 2005; 116: 624-33.

[69] Nedelcu G. Magnetic nanoparticles impact on tumoral cells in the treatment by magnetic fluid hyperthermia. Digest J Nanomater Biostruct 2008; 3(3): 103-17.

[70] Khanafer KK, Vafai KA, Kangarlu A. Water diffusion in biomedical systems as related to magnetic resonance imaging. Magn Reson Imaging 2003; 21: 17-31.

[71] Sonvico F, Mornet S, Vasseur S, et al. Folate-conjugated ironoxide nanoparticles for solid tumor targeting as potential specific magnetic hyperthermia mediators: Synthesis, physiochemical characterization, and in vitro experiments. Bioconjug Chem 2005; 16: 1181-8.

[72] Kim S, Loevner LA, Quon H, et al. Prediction of response to chemoradiation therapy in squamous cell carcinomas of the head and neck using dynamic contrast-enhanced mr imaging. AJNR Am J Neuroradiol 2010; 31: 262-8.

[73] Moroz P, Jones SK, Gray BN. Tumor response to aterial embolization hyperthermia and direct injection hyperthermia in a rabbit liver tumor model. J Surg Oncol 2002; 80: 149-56.

[74] Kraus RH, Wright B. In: Biomedical applications of nanotechnology. In: Labhasetwar V, Leslie-Pelecky DL, Eds.Magnetic nanoparticles in cancer diagnosis and hyperthermic treatment. John Wiley and Sons, Inc. 2007; pp. 65-82.

[75] Silver FH. Mechanochemical transduction and its role in biology. In: Mechanosensing and mechanochemical transduction in extracellular matrix biological, chemical, engineering, and physiological aspects. US Springer Verlag 2002: pp. 262-70.

[76] Hayek SS, Sharma R, Kwon S, Sharma A, Chen CJ. Temperature and magnetic resonance characteristics of zinc, manganese, gadolinium, gold, iron magnetic nanoparticles and cytokine synergy in hyperthermia. J Biomed Sci Eng 2008; 1(3):147-209.

[77] Brusentsov N, Nikitin L, Brusentsova T, et al. Magnetic fluid hyperthermia of the mouse experimental tumor. J Magn Magn Matr 2002; 252: 378-80.

[78] Cho YW, Park SA, Han TH, et al. In vivo tumor targeting and radionuclide imaging with self-assembled nanoparticles: mechanisms, key factors, and their implications. Biomaterials 2007; 28(6):1236-47.

[79] Nigavekar SS, Sung LY, Llanes M, et al. 3H Dendrimer Nanoparticle Organ/Tumor Distribution. Pharm Res 2004; 21(3):476-83.

[80] Jonsson PE, Garcia-Palacios JL, Hansen MF, Norblad P. Relaxation in interacting nanoparticel systems. J Mol Liq 2004; 114: 1315.

[81] MacFall JR, Prescott DM, Charles HC. MRI phase thermometry in vivo in canine brain, muscle, and tumor tissue. Med Phys 1996; 23(10): 1775-82.

[82] Haemmerich D, Santos I, Schutt DJ, Webster JG, Mahvid DM. In vitro measurements of temperature-dependent specific heat of liver tissue. Med Eng Phys 2006; 28: 194-7.

[83] Maswadi SM, Dodd SJ, Gao JH, Glickman RD. Temperature mapping of laser-induced hyperthermia in an ocular phantom using magnetic resonance thermography. J Biomed Opt 2004; 9(4): 7118 .

[84] Amao Y, Okura I. Fullerene C60 immobilized in polymethylmethacrylate film as an optical temperature sensing material. Analysis 2000; 28: 847-9.

[85] Smith CR, Sabatino DR, Praisner TJ. Temperature sensing with thermochromic liquid crystals. Exp Fluids 2001; 30: 190-201.

[86] Maqueda RJ, Wurden GA, Terry JL, Stillerman JA. The new infrared imaging sysem on Alcator C-Mod. Rev Sci Instrum 2000; 70: 734-7.

[87] Settecase F, Sussman MS, Roberts TPL. A new temperaturesensitive contrast mechanism for mri: curie temperature transitionbased imaging. Contrast Media Mol Imaging 2007; 2: 50-54.

[88] Auzans E, Zins D, Blums E, Massart R. Synthesis and properties of Mn-Zn ferrite ferrofluids. J Mater Sci 1999; 34: 1253-60.

[89] Warheit DB, Sayes CM, Reed KL. Nanoscale and fine zinc oxide particles: can in vitro assays accurately forecast lung hazards following inhalation exposures? Environ Sci Technol 2009; 43(20): 7939-45.

[90] Babincov M, Altanerov V, Altaner C, Bergemann C, Babinec P. In vitro analysis of cisplatin functionalized magnetic nanoparticles in 
combined cancer chemotherapy and electromagnetic hyperthermia. IEEE Trans Nanobiosci 2008; 7(1): 15-9.

[91] Villa A, Gill H, McCallion O, Alonso M. Transport of PLA-PEG particles across the nasal mucosa: effect of particle size and PEG coating density. J Control Release 2004; 98: 231-44.

[92] Krause W, Hackmann-Schlichter N, Franz Karl Maier FK, Müller R. Dendrimers in diagnostics. In: Topics in current chemistry. dendrimers ii architecture, nanostructure and supramolecular chemistry. Berlin: US Springer Link 2000; 210: 261-308.

[93] Brusentsova TN, Brusentsov NA, Kuznetsov VD, Nikiforov VN. Synthesis and investigation of magnetic properties of Gdsubstituted $\mathrm{Mn}-\mathrm{Zn}$ ferrite nanoparticles as a potential low- $T_{\mathrm{C}}$ agent for magnetic fluid hyperthermia. J Magn Magn Mater 2005; 293(1): 298-302.

[94] Jennifer A, Nelson, Lawrence H. Bennett, Michael J. Wagner Solution, synthesis of gadolinium nanoparticles. J Am Chem Soc 2002; 124(12): $2979-83$.

[95] Turner JL, Pan D, Plummer R, Chen Z, Whittaker AK, Wooley KL. Synthesis of gadolinium-labeled shell-crosslinked nanoparticles for magnetic resonance imaging applications. Adv Funct Mater 2005; 15(8): 1248-54

[96] Wlodarczyk W, Boroschewski R, Hentschel M, Wust P, Mönich G, Felix R. Three-dimensional monitoring of small temperature changes for therapeutic hyperthermia using MR. J Magn Reson Imaging 2005; 8(1):165-74.

[97] de Senneville BD, Mougenot C, Quesson B, Dragonu I, Grenier N, Moonen CT. MR thermometry for monitoring tumor ablation. Eur Radiol 2007; 17(9): 2401-10.

[98] Arthur RM, Straube WT, Trobaugh JW, Moros EG. Non-invasive estimation of hyperthermia temperatures with ultrasound. Int J Hyperthermia 2005; 21(6): 589-600.

[99] Catherina SP, van Rijswijk, Geirnaerdt MJA, et al. Dynamic contrast-enhanced MR imaging in monitoring response to isolated limb perfusion in high-grade soft tissue sarcoma: initial results. Eur Radiol 2003; 13(8): 1849-58

[100] Fortin JP, Wilhelm C, Gazeau F, et al. Use of magnetic nanoparticles as intracellular agents for hyperthermia. Contrast Media Mol Imaging 2006; 1(2): 56-7.

[101] Kussman BD, Mulkern RV, Holzman RS. Iatrogenic hyperthermia during cardiac magnetic resonance imaging. Anesth Analg 2004; 99:1053-5.

[102] Reinl HM, Peller M, Hagmann M, Turner P, Issels R, Reiser M. Ferrite-enhanced MRI monitoring in hyperthermia. Magn Reson Imaging 2005; 23(10): 1017-20.

[103] Peller M. Hyperthermia induces T1 relaxation and blood flow changes in tumors. A MRI thermometry study in vivo. Magn Reson Imaging 2003; 21(5): 545-51.

[104] Karam JA, Mason RP, Koeneman KS, Antich PP, Benaim EA, Hsieh TJ. Molecular Imaging in Prostate Cancer. J Cell Biochem 2003; 90: 473-83.

[105] Cheng KH, Hernandez M. Magnetic resonance diffusion imaging detects structural damage in biological tissues upon hyperthermia. Cancer Res 1992; 52(11): 6066-73.

[106] Ponce AM, Viglianti BL, Yu D, et al. Magnetic resonance imaging of temperature-sensitive liposome release: drug dose painting and antitumor effects. J Natl Cancer Inst 2007; 99(1): 53-63.

[107] Hey S, Maclair GB, de Senneville D, et al. Online correction of respiratory-induced field disturbances for continuous MRthermometry in the breast. Magn Reson Med 2009; 61(6): 1494-9.

[108] Kircher MF, Mahmood U, King RS, Weissleder R, Josephson L. A multimodal nanoparticle for preoperative magnetic resonance imaging and intraoperative optical brain tumor delineation. Cancer Res 2003; 63: 8122-5.

[109] Sosnovik DE, Schellenberger EA, Nahrendorf M, et al. Magnetic resonance imaging of cardiomyocyte apoptosis with a novel magneto-optical nanoparticle. Magn Reson Med 2005; 54: 718-24.

[110] Veiseh O, Sun C, Gunn J, et al. Optical and MRI multifunctional nanoprobe for targeting gliomas. Nano Lett 2005; 5: 1003-8.

[111] Yu SB, Watson AD. Metal-based X-ray contrast media. Chem Rev 1999; 99(9): 2353-78.

[112] Ritman EL. Molecular imaging in small animals - roles for microCT. J Cell Biochem 2002; 87(39): 116-24.

[113] Chivukula VS, Shur MS, Ciplys D. Recent advances in application of acoustic, acousto-optic and photoacoustic methods in biology and medicine. Phys Status Solidi(A) 2007; 204(10): 3209-36.

[114] Li FR, Yan WH, Guo YH, Qi H, Zhou HX. Preparation of carboplatin-Fe@C-loaded chitosan nanoparticles and study on hyperthermia combined with pharmacotherapy for liver cancer. Int J Hyperthermia $2009 ; 25(5): 383-91$.
[115] Martina MS, Fortin JP, Menager C, et al. Generation of superparamagnetic liposomes revealed as highly efficient MRI contrast agents for in vivo imaging. J Am Chem Soc 2005; 127: 10676-85.

[116] Romanus E, Huckel M, Gross C, et al. Magnetic nanoparticles relaxation measurement as a novel tool for in vivo diagnostics. J Magn Magn Mater 2002; 252: 387-9.

[117] McDermott R, Kelso N, Lee SK, et al. SQUID-detected magnetic resonance imaging in microtesla magnetic fields. J Low Temp Phys 2004; 135: 793-821.

[118] Allen M, Bulte JWM, Liepold L, et al. paramagnetic viral nanoparticles as potential high-relaxivity magnetic resonance contrast magnets. Magn Reson Med 2005; 54: 807-12.

[119] Plassat V, Martina MS, Barratt G, Ménager C, Lesieur S. Sterically stabilized superparamagnetic liposomes for MR imaging and cancer therapy: pharmacokinetics and biodistribution. Int J Pharm 2007; 344(1-2): 118-27.

[120] Alexiou, C, Arnold W, Hulin P, Klein RJ, Renz H, Parak FG, et al. Magnetic mitoxantrone nanoparticle detection by histology, X-ray and MRI after magnetic tumor targeting. J Magn Magn Mater 2001; 225: 187-193.

[121] Zhao, M, Beauregard DA, Loizou L, Davletov B, Brindle KM. Non-invasive dtection of apoptosis using magnetic resonance imaging and a targeted contrast agent. Nat Med 2001; 7: 1241-3.

[122] Bodurka J, Bandettini PA. Toward direct mapping of neuronal activity: MRI detection of ultraweak, transient magnetic field changes. Magn Reson Med 2002; 47: 1052-8.

[123] Konn,D, Gowland P, Bowtell R. MRI detection of weak magnetic fields due to an extended current dipole in a conducting sphere: A model for direct detection of neuronal currents in the brain. Magn Reson Med 2003; 50(1): 40-49.

[124] McDermott R, Trabesinger AH, Muck M, Hahn EL, Pines A, Clarke J. Liquid-state NMR and scalar coupling in microtesla magnetic fields. Science 2002; 295: 2247-9.

[125] Volegov P, Matlachov AN, Espy MA, George JS, Kraus RH Jr. Simultaneous magnetoencephalography and SQUID detected nuclear MR in microtesla magnetic fields. Magn Reson Med 2004; (52)3: 467-70

[126] Romanus E, Berkov DV, Prass S, Grob C, Weitschies W, Weber P. Determination of energy barrier distributions of magnetic nanoparticles by temperature dependent magnetorelaxometry. Nanotechnology 2003; 14: 1251-4.

[127] Sharma R. Kwon S. New applications of nanoparticles in cardiovascular imaging. J Exp Nanosci 2007; 2(1): 115-23.

[128] Matlachov AN, Volegov PL, Espy MA, Kraus RH. SQUID detected NMR in microtesla magnetic fields. J Magn Reson 2004; 170: $1-7$

[129] Huff TB|, Tong L!, Zhao Y!, Hansen MH, Cheng JX|, Wei A. Hyperthermic effects of gold nanorods on tumor cells. Nanomedicine 2007; 2(1): 125-32.

[130] Visaria RK, Griffin RJ, Williams BW, et al. Enhancement of tumo thermal therapy using gold nanoparticle-assisted tumor necrosis factor- $\alpha$ delivery. Mol Cancer Ther 2006; 5:1014-20.

[131] Wijaya A, Brown KA, Alper JD, Hamad-Schifferli K. Magnetic field heating study of Fe-doped Au nanoparticles. J Magn Magn Mater 2007; 309(1): 15-9.

[132] Huang WC, Chen YC. Photochemical synthesis of polygonal gold nanoparticles. J Nanopart Res 2008; 10(4): 697-702.

[133] Katti KV, Kannan R, Katti K, et al. Hybrid gold nanoparticles in molecular imaging and radiotherapy Czech J Phys 2006; 56(1):2334.

[134] Alric C, Taleb J, Le Duc G, et al. Gadolinium chelate coated gold nanoparticles as contrast agents for both X-ray computed tomography and magnetic resonance imaging. J Am Chem Soc 2008; 130(18): 5908-15

[135] Mallidi S, Larson T, Aaron J, Sokolov K, Emelianov S. molecular specific optoacoustic imaging with plasmonic nanoparticles. Opt Express 2007; 15(11): 6583-8.

[136] Brusentsova TN, Kuznetsov VD. Synthesis and investigation of magnetic properties of substituted ferrite nanoparticles of spinel system $\mathrm{Mn}_{1-\mathrm{x}} \mathrm{Zn}_{\mathrm{x}}\left[\mathrm{Fe}_{2-\mathrm{y}} \mathrm{L}_{\mathrm{y}}\right] \mathrm{O}_{4}$. J Magn Magn Mater 2007; 311(1): $22-5$.

[137] Sutariya GM, Vincent D, Bayard B, Upadhyay RV, Noyel G, Mehta RV. Magnetic DC field and temperature dependence on complex microwave magnetic permeability of ferrofluids: effect of constituent elements of substituted Mn ferrite. J Magn Magn Mater 2003; 260(1-2): 42-7.

[138] Sharma R. Gadolinium Toxicity: epidermis thickness measurement by magnetic resonance imaging at $500 \mathrm{MHz}$. Skin Res Technol 2010; 28(5): 339-53 
[139] Caravan P. Protein-targeted gadolinium-based magnetic resonance imaging (MRI) contrast agents: design and mechanism of action. Acc Chem Res 2009; 42(7): 851-62.

[140] Drake P, Cho HJ, Shih PS, et al. Gd-doped iron-oxide nanoparticles for tumour therapy via magnetic field hyperthermia. J Mater Chem 2007; 17: 48्14.

[141] Uskoković W, Ko ${ }^{5}$ ak A, Drofenik M, Drofenik M. Preparation of Silica-Coated Lanthanum-Strontium manganite particles with designable Curie Point, for application in hyperthermia treatments. Int J Appl Ceram Tech 2006; 3(2): 134-43.

[142] Ying-ying G, Tan Xiao-ping T, Shu-quan L, Shang-bin S. Effects of $\mathrm{La}^{3+}$ doping on $\mathrm{MnZn}$ ferrite nanoscale particles synthesized by hydrothermal method. J Central South Univ Technol 2004; 11(2): 113-228.

[143] Shuai J, Parker I. Optical single-channel recording by imaging $\mathrm{Ca}^{2+}$ flux through individual ion channels: theoretical considerations and limits to resolution. Cell Calcium 2005; 37(4): 283-99.

[144] Demuro A, Parker I. Imaging single-channel calcium microdomains. Cell Calcium 2006; 40(5-6): 413-22.

[145] Hou CH, Chen CW, Hou SM, Li YT, Lin FH. The fabrication and characterization of dicalcium phosphate dihydrate-modified magnetic nanoparticles and their performance in hyperthermia processes in vitro. Biomaterials 2009; 30(27): 4700-7.

[146] Hou CH, Hou SM, Hsueh YS, Lin J, Wu HC, Lin FH. The in vivo performance of biomagnetic hydroxyapatite nanoparticles in cancer hyperthermia therapy. Biomaterials 2009; 30(23-24): 3956-60.

[147] Buzas CJ, Pacher P, Rosenberg H, Hajnoczky G. Single cell calcium imaging cell calcium imaging studies of pathomchanism of malignant hyperthermia. Biophys J 2002; 82 (1): 649.

[148] Plotkin M, Gneveckow U, Meier-Hauff K, et al. 18F-FET PET for planning of thermotherapy using magnetic nanoparticles in recurrent glioblastoma. Int J Hyperthermia 2006; 22(4): 319-25.

[149] Lanza GM, Winter PM, Caruthers SD, et al. Magnetic resonance molecular imaging with nanoparticles. J Nucl Cardiolol 2004; 11:733-743.

[150] Nahrendorf M, Zhang H, Hembrador S, et al. Nanoparticle PETCT imaging of macrophages in inflammatory atherosclerosis. Circulation 2008; $117(3): 379-87$.

[151] Palussière J, Salomir R, Bail BL, Fawaz R, Quesson B, Grenier N, Moonen CTW. Feasibility of MR-guided focused ultrasound with real-time temperature mapping and continuous sonication for ablation of VX2 carcinoma in rabbit thigh. Magn Reson Med 2002; 47 (6):1065-72.

[152] Corchero JL, Villaverde A. Biomedical applications of distally controlled magnetic nanoparticles. Trends Biotechnol 2009; 27(8): 468-76.

[153] Statford IJ, Adams GE. Effect of hyperthermia on differential cytotoxiciy of a hypoxic cell radiosensitizer Ro-07-0582 on mammalian cells in vitro. Radiat Res 1976; 67 (3): 459-73.

[154] Emi, Maehara Y, Kusumoto T, Baba H, Sakaguchi M, Sugimachi $\mathrm{K}$. Hyperthermia enhances the cytotoxicity against hypoxic cells of RP-170, a new 2-nitroimidazole nucleoside hypoxic cell sensitizer. Oncology 1995; 52: 55-9.

[155] Tamuelvicius P, George KC, Rücker A, Streffer C. Effects of local hyperthermia on the tissue levels and toxicity of three radiosensitizers in mice. Int J Hyperthermia 1992; 8(3): 321-8.

[156] Teicher BA, Herman TS, Holden SA, Jones SM. Addition of misonidazole, etanidazole, or hyperthermia to treatment with fluosol da/carbogen/radiation. J Natl Cancer Inst 1989; 81(12): 929-34.

[157] Walton MI, Bleehen NM, Workman P. Stimulation by localized tumor hyperthermia of reductive bioactivation of 2-nitroimidazole benznidazole in mice. Cancer Res 1989; 49: 2351-5.

[158] Herman TS, Teicher BA, Holden SA, Pfeffer MR, Jones SM. Addition of 2-nitroimidazole radiosensitizers to cis-diamminedichloroplatinum(II) with radiation and with or without hyperthermia in the murine FSaIIC fibrosarcoma. Cancer Res 1990; 50(9): 2734-40.
[159] Fujimoto S, Ohta M, Shrestha RD, et al. Enhancement of hyperthermochemotherapy for human gastric cancer in nude mice by thermosensitization with nitroimidazoles. Br J Cancer 1988; 58(1): 42-5.

[160] Mahy P, Geets X, Lonneux M, et al. Determination of tumour hypoxia with $[18 \mathrm{~F}] \mathrm{EF} 3$ in patients with head and neck tumours: a phase I study to assess the tracer pharmacokinetics, biodistribution and metabolism. Eur J Nucl Med Mol Imaging 2008; 35(7): 12829.

[161] Procissi D, Claus F, Burgman P, et al. In vivo 19F magnegnetic resonance spectroscopy and chemical shift imaging of tri-fluoronitroimidazole as a potential hypoxia reporter in solid tumors. Clin Cancer Res 2007; 13(12): 3738-47.

[162] Jaiswal MK, Banerjee R, Pradhan P, Bahadur D. Thermal behavior of magnetically modalized poly(N-isopropylacrylamide)-chitosan based nanohydrogel. Colloids Surf B Biointerfaces 2010; 81(1): 185-94.

[163] Johannsen M, Thiesen B, Wust P, Jordan A. Magnetic nanoparticle hyperthermia for prostate cancer. Int J Hyperthermia 2010; 26(8): 790-5.

[164] Yang C, Jie R, Jianbo L, Yan L. Thermo-responsive MnZnFerrite/Poly(N,N'-Isopropyl Acrylamide-co-N-Hydroxymethylacrylamide) core/shell nanocomposites for drug-delivery systems. J Biomater Sci Polym Ed 2010; [Epub ahead of print].

[165] Sirotkina MA, Elagin VV, Shirmanova MV, et al. OCT-guided laser hyperthermia with passively tumor-targeted gold nanoparticles. J Biophotonics 2010; 3(10-11): 718-27.

[166] Martín-Saavedra FM, Ruíz-Hernández E, Boré A, Arcos D, ValletRegí M, Vilaboa N. Magnetic mesoporous silica spheres for hyperthermia therapy. Acta Biomater 2010; 6(12): 4522-31.

[167] Sanson C, Diou O, Thévenot J, et al. Doxorubicin loaded magnetic polymersomes: theranostic nanocarriers for MR imaging and magneto-chemotherapy. ACS Nano 2011; 5(2): 1122-1140.

[168] Sato A, Tamura Y, Sato N, et al. Melanoma-targeted chemothermo-immuno (CTI)-therapy using N-propionyl-4-Scysteaminylphenol-magnetite nanoparticles elicits CTL response via heat shock protein-peptide complex release. Cancer Sci 2010; 101(9): 1939-46.

[169] Giordano MA, Gutierrez G, Rinaldi C. Fundamental solutions to the bioheat equation and their application to magnetic fluid hyperthermia. Int J Hyperthermia 2010; 26(5): 475-84.

[170] Cheng KS, Stakhursky V, Stauffer P, Dewhirst M, Das SK. Online feedback focusing algorithm for hyperthermia cancer treatment. Int J Hyperthermia 2007; 23(7): 539-54.

[171] Stakhursky VL, Arabe O, Cheng KS, et al. Real-time MRI-guided hyperthermia treatment using a fast adaptive algorithm. Phys Med Biol 2009; 54(7): 2131-45.

[172] Cheng KS, Dewhirst MW, Stauffer PR, Das S. Effective learning strategies for real-time image-guided adaptive control of multiplesource hyperthermia applicators. Med Phys 2010; 37(3): 1285-97.

[173] Ahamed M, Akhtar MJ, Siddiqui MA, et al. Oxidative stress mediated apoptosis induced by nickel ferrite nanoparticles in cultured A549 cells. Toxicology 2011 Mar 4; [Epub ahead of print].

[174] Liu L, Ni F, Zhang J, Jiang X, Lu X, Guo Z, Xu R. Silver nanocrystals sensitize magnetic-nanoparticle-mediated thermo-induced killing of cancer cells. Acta Biochim Biophys Sin (Shanghai) 2011 Mar 3; [Epub ahead of print].

[175] Tagami T, Ernsting MJ, Li SD. Efficient tumor regression by a single and low dose treatment with a novel and enhanced formulation of thermosensitive liposomal doxorubicin. J Control Release 2011 Feb 19; [Epub ahead of print].

[176] Wu YN, Chen DH, Shi XY, Lian CC, Wang TY, Yeh CS, Ratinac KR, Thordarson P, Braet F, Shieh DB. Cancer-cell-specific cytotoxicity of non-oxidized iron elements in iron core-gold shell NPs. Nanomedicine 2011 Jan 25; [Epub ahead of print].

(C) Sharma et al.; Licensee Bentham Open.

This is an open access article licensed under the terms of the Creative Commons Attribution Non-Commercial License (http://creativecommons.org/licenses/by-nc/3.0/) which permits unrestricted, non-commercial use, distribution and reproduction in any medium, provided the work is properly cited. 